\title{
Rheological Properties Comparing Hot and Cold Bituminous Mastics Containing Jet Grouting Waste
}

\author{
Rosa Veropalumbo (iD, ${ }^{1}$ Francesca Russo ${ }^{1},{ }^{1}$ Nunzio Viscione, ${ }^{1,2}$ \\ and Salvatore A. Biancardo (iD) \\ ${ }^{1}$ Department of Civil, Architectural and Environmental Engineering, Federico II University of Naples, Via Claudio 21, \\ 80125 Naples, Italy \\ ${ }^{2}$ Iterchimica Srl, Via Guglielmo Marconi, 21, 24040 Suisio, BG, Italy
}

Correspondence should be addressed to Rosa Veropalumbo; rosa.veropalumbo@unina.it

Received 6 November 2019; Revised 12 January 2020; Accepted 23 January 2020; Published 22 February 2020

Guest Editor: Andrea Grilli

Copyright (c) 2020 Rosa Veropalumbo et al. This is an open access article distributed under the Creative Commons Attribution License, which permits unrestricted use, distribution, and reproduction in any medium, provided the original work is properly cited.

The use of reclaimed asphalt pavement is a practice that is adding significant environmental value to road technologies, not only due to the reduction of materials sent to landfill but also because of the mechanical properties of the reclaimed asphalt (RA) that can be reused. This research focuses on the rheological properties of hot and cold bituminous mastics made up as follows: (1) hot mastics mixed with limestone filler (LF) and bitumen, (2) hot mastics, made from bitumen mixed with jet grouting waste (JW), a mixture of water, cement, and soil derived from land consolidation work in underground tunnels, and (3) hot mastics mixed with LF and JW as filler and bitumen. Three different ratios (0.3, 0.4, and 0.5) of filler per unit of neat bitumen (B50/70) were studied. The same number was used for mixing cold mastics, by using an appropriate laboratory protocol designed since the adoption of a cationic bituminous emulsion. A total of 18 mastics were prepared and investigated. The comparison was carried out using the frequency sweep (FS) test, analysing shear modulus $G^{*}$, applying the multistress creep and recovery (MSCR) test $\left(40^{\circ} \mathrm{C}\right.$ and $\left.60^{\circ} \mathrm{C}\right)$ as well as the delta ring and ball $(\triangle \mathrm{R} \& \mathrm{~B})$ test, focusing on two main issues: (1) the stiffening effect caused by the filler type used for mixing each mastic, and (2) a comparison, in terms of stiffening effects and nonrecoverable creep compliance $\left(J_{\mathrm{nr}}\right)$ of hot and cold mastic performance to highlight JW reuse in mastics. The results showed that the best $G^{*}$ performance at test temperatures higher than $30^{\circ} \mathrm{C}$ is given by cold mastic after 28 days of curing time when JW is added to LF and bitumen. The lowest $J_{\mathrm{nr}}$ value was $40^{\circ} \mathrm{C}$ and $60^{\circ} \mathrm{C}$ for the same mastic.

\section{Introduction}

Pavement engineering researchers have been developing numerous new technologies to achieve more environmentfriendly and energy-efficient pavement maintenance/construction solutions in order to reduce the costs of maintenance operations, enhancing and redeveloping road heritage [1]. Since road maintenance involves milling existing old layers (RA) [2], the cold recycling technique has become an increasingly popular alternative for road pavement construction as it minimizes financial and environmental impact through high performance.

Cold recycling techniques provide considerable advantages, i.e., limited exploitation of environmental resources due to reduced aggregate extraction, greater productivity throughout the entire process, and, on the same layer, they offer identical levels of durability as layers made from virgin materials, energy savings by reducing the temperatures for heating virgin aggregates and, in the case of on-site recycling, the transportation of materials to and from the work site is eliminated, in addition to reductions in fuel fumes, dust, and gas released into the atmosphere from heating and transportation.

A validated design procedure for cold bituminous mixtures is not yet available, and many researchers are trying to develop a more appropriate procedure [3].

Flores et al. [4], for example, proposed a design methodology for cold recycled emulsion mixtures, evaluating air 
void content, indirect tensile stress (ITS), indirect tensile strength ratio (ITSR), rutting resistance, stiffness modulus, and fatigue damage. They studied a series of possible dosages of bituminous emulsion contents of 2,3 , and $4 \%$ and cement contents of 0,1 , and $2 \%$ over the weight of the aggregates; in light of the results of the laboratory tests, a methodology was proposed and a single value "GPI" (Global Performance Index) has been proposed, taking into account the results obtained from previous laboratory tests. The results showed a strong relationship between GPI with gradation curves, bituminous emulsions, and cement.

$\mathrm{Du}$ [5] proposed a mix design procedure based first of all on a preliminary investigation of an optimum water content to add to an optimum bituminous emulsion content to investigate the properties of a cold recycled mixture made up of composite Portland cement (CPC), hydrated lime (HL), and a combination of hydrated lime and ground-granulated blastfurnace slag (GGBF). The CPC helped reach best performance in terms of ITS, moisture, and rutting resistance.

RA gradation does not always meet the requirements of technical specifications, and virgin aggregates and filler powders need to be added. Lyu et al. [6], for example, suggested a potentially effective mix design made up of $3.8 \%$ bituminous emulsion, $2 \%$ cement, $80 \%$ RA, and $20 \%$ virgin aggregates.

Kuna and Guttumukkala [7] further investigated the performance of cold reclaimed asphalt pavement using the dynamic modulus. The results showed that cold mixtures have lower entity variation from the highest to lowest temperatures compared with hot mix asphalt (HMA), where higher increments occur.

Filler is added to correct the lower part of a granulometric curve for both cold and hot mixture and to fill the gaps between grains left by larger elements. The filler bonds closely with the binder to form a bituminous mastic, which envelops the stone phase and provides full cohesion through the entire mixture, affecting the final stiffness of the mixture. The stress-strain response of flexible pavements is strictly linked to the rheological behaviour of the binder and its interaction with the lithic skeleton.

Many studies have focused on investigating the properties of the mastics with reference to cold bituminous mixture with RA.

Godenzoni et al. [8] evaluated the effects of different mineral fillers on the linear viscoelastic (LVE) properties of cold bituminous mastics. The shear modulus was measured on bituminous mastics prepared with calcium carbonate and cement as filler at filler-to-bitumen volume ratios of 0.15 and 0.3 . It has been shown that $G^{*}$ values are higher for mastics containing cement than those containing calcium carbonate as an added mineral; specifically, $G^{*}$ increases with a higher cement concentration ratio and LVE behaviour evolves from that of liquid material to that of solid material.

Some studies have shown that the multistress creep and recovery (MSCR) method is the most appropriate for measuring the rutting resistance performance of asphalt binder. Indeed, it is widely accepted that, compared to the existing superpave rutting factor $G^{*} / \sin \delta(\delta=$ phase angle), nonrecoverable creep compliance $\bar{J}_{\mathrm{nr}}$ following the MSCR test is more closely related to the rutting resistance performance of asphalt mixture [6].

Vignali et al. [9] have measured to what extent cement and limestone filler contents affect the rutting response of two mastics produced using cationic bituminous emulsion: (1) $75 \%$ bitumen and $25 \%$ cement and (2) $75 \%$ bitumen, $12.5 \%$ filler, and $12.5 \%$ cement per volume. The results have confirmed that the presence of limestone filler improves mastic stiffness at high temperatures with a $G^{*}$ higher than mastic with cement; this was confirmed by the MSCR results, where the mastic containing limestone filler accumulated less deformation at both test temperatures $\left(46^{\circ} \mathrm{C}\right.$ and $\left.58^{\circ} \mathrm{C}\right)$ and both stress levels $(0.1 \mathrm{kPa}$ and $3.2 \mathrm{kPa})$.

Garilli et al. [10] focused on asphalt emulsion cement (AEC) mastic mixing to evaluate the behaviour of cold inplace recycling in the phase of coexistence of viscoelastic and brittle materials using a bending beam rheometer (BBR). The authors proposed introducing glass microspheres to act as an "inert solid skeleton" in the production of AEC mastics for BBR prismatic beams, to study the interaction between bituminous emulsion and cement in thin film, and to limit the specimens' shrinkage and warpage during the curing period.

Following the main results available in scientific literature on cold bituminous mixtures (CBM) and mastics, the research presented here aims to bridge a gap in the laboratory protocol for mixing the cold bituminous mastics and to appreciate the main differences in relation to hot bituminous mastics.

Different mastics were prepared based on a filler-tobitumen weight ratio of $0.3,0.4$, and 0.5 . The fillers adopted were of the limestone (LF) and jet grouting waste (JW) types, while neat bitumen 50/70 (B50/70) was adopted for hot mastics, and bituminous emulsion (BE) made up of $60 \%$ neat bitumen and $40 \%$ water was used for the cold ones; mixing was carried out without adding cement traying to substitute it with JW in the cold bituminous mixture production since the JW is also a mixture made up of cement.

$G^{*}$ (at $10,20,30,40,50$, and $60^{\circ} \mathrm{C}$, at frequencies from $0.1 \mathrm{~Hz}$ to $10 \mathrm{~Hz}$ ), MSCR (test temperatures $40^{\circ} \mathrm{C}$ and $60^{\circ} \mathrm{C}$ at $0.1 \mathrm{kPa}$ and $3.2 \mathrm{kPa})$, and delta ring and ball $(\Delta \mathrm{R} \& \mathrm{~B})$ tests were performed for all mastics. Figure 1 shows the flowchart for the number of specimens in the series of experiments.

\section{Materials and Methods}

2.1. Materials. Different mastics were prepared according to the filler-to-bitumen ratios of $0.3,0.4$, and 0.5 . Three types of mastics were prepared for each ratio: (1) LF plus B50/70 (hot) and LF plus BE (cold), (2) JW plus B50/70 (hot) and JTW plus BE (cold), and (3) JW plus LF plus B50/70 (hot) and JW plus LF plus EB (cold).

JW is a mixture of water and cement injected into the soil at high pressure; its element composition is shown in Table 1(a), where the presence of calcium (25.7\%), silicon (67.6\%), magnesium (1.7\%), and other elements $(0.006 \%)$ can be observed.

Before moving on to mastic preparation, the JW was subjected to a crushing process using a ball mill and curve gradation measurement (Figure 2). 


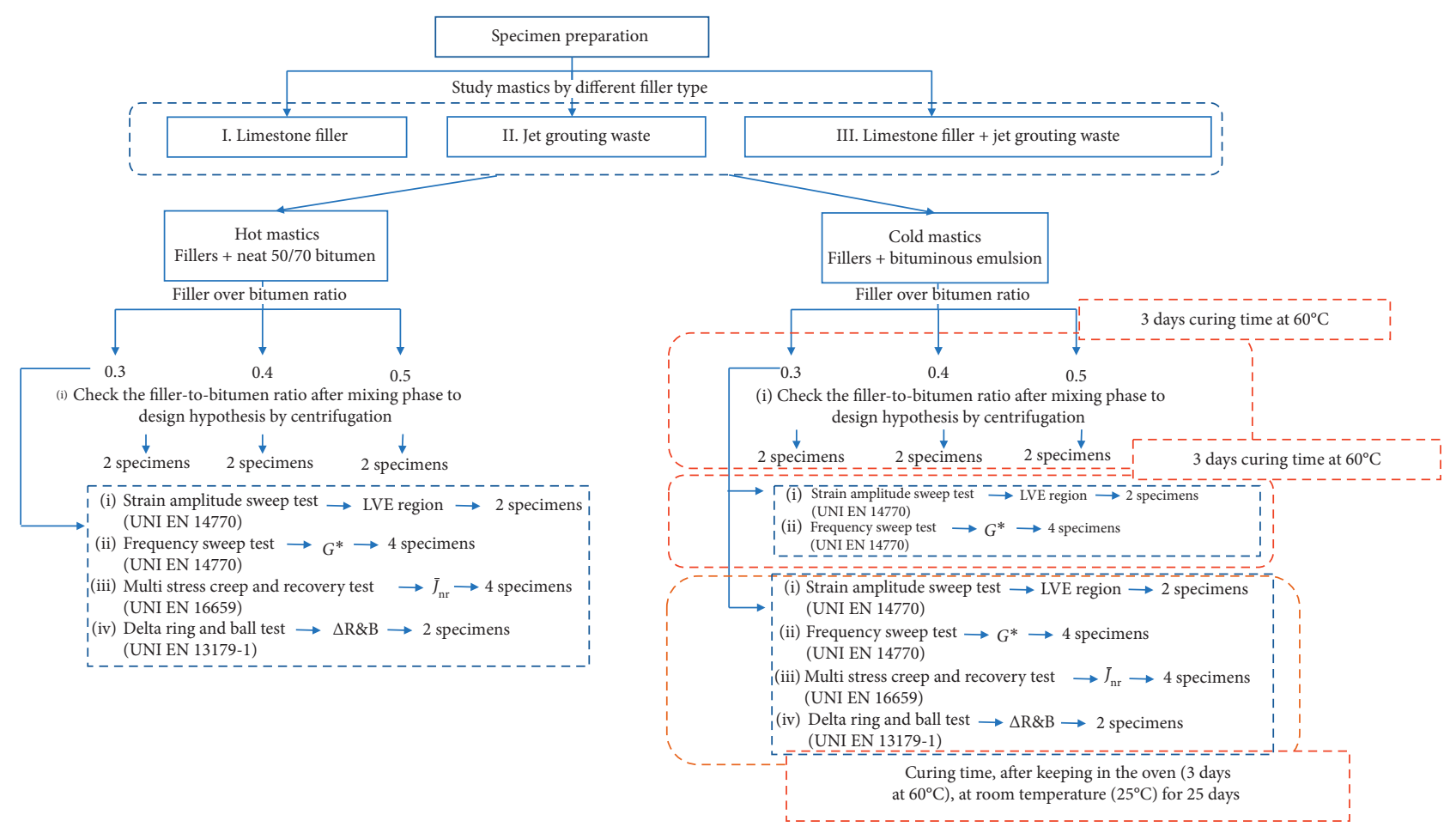

FIGURE 1: Flowchart for the mixed specimens in laboratory investigations.

TABLE 1: Main properties of materials: (a) chemical composition of JW filler, and (b) JW and LF specific gravity and Rigden voids.

\begin{tabular}{|c|c|c|}
\hline \multicolumn{3}{|l|}{ (a) } \\
\hline Elements & \multicolumn{2}{|c|}{ Results (\%) } \\
\hline $\mathrm{Ca}$ & \multicolumn{2}{|c|}{25.701} \\
\hline $\mathrm{Fe}$ & \multicolumn{2}{|c|}{4.859} \\
\hline $\mathrm{Si}$ & \multicolumn{2}{|c|}{67.642} \\
\hline $\mathrm{Mg}$ & \multicolumn{2}{|c|}{1.735} \\
\hline As & \multicolumn{2}{|c|}{0.003} \\
\hline $\mathrm{Be}$ & \multicolumn{2}{|c|}{0.003} \\
\hline Co & \multicolumn{2}{|c|}{0.004} \\
\hline $\mathrm{Cr}$ & \multicolumn{2}{|c|}{0.008} \\
\hline $\mathrm{Ni}$ & \multicolumn{2}{|c|}{0.004} \\
\hline $\mathrm{Cu}$ & \multicolumn{2}{|c|}{0.007} \\
\hline $\mathrm{Zn}$ & \multicolumn{2}{|c|}{0.026} \\
\hline Others* & \multicolumn{2}{|c|}{0.006} \\
\hline \multicolumn{3}{|l|}{ (b) } \\
\hline Filler & Specific gravity $\left(\mathrm{g} / \mathrm{cm}^{3}\right)$ & Rigden voids (\%) \\
\hline LF & 2.737 & 41.440 \\
\hline JW & 2.687 & 51.360 \\
\hline
\end{tabular}

${ }^{*} \mathrm{Sn}, \mathrm{V}, \mathrm{Cd}, \mathrm{Ti}$, and $\mathrm{Mn}$.

LF and JW (see main properties in Table 1(b)) were adopted in bituminous mastics production as a total passing through a $0.063 \mathrm{~mm}$ sieve.

Hot and cold mastics were prepared: hot-process neat bitumen $50 / 70$ produced by an oil refinery in southern Italy was used, while a bituminous emulsion mixture of $60 \%$ neat bitumen $50 / 70$ and $40 \%$ water was used for the cold process.

The main properties of the bitumen and bituminous emulsion are shown in Table 2.
2.2. Mastic Preparation. The mastics were prepared adopting two different laboratory protocol procedures for hot and cold mastics.

For the hot mastics, suitable mixing temperatures were chosen according to AASHTO T316 using rotational viscosimetry. An RW 20 DZM N mechanical mixer was used to mix the filler and binder at the traditional temperature of $150^{\circ} \mathrm{C}$ used for the HMA mixture.

The mixing process was performed carefully to obtain homogenous matrices: a stainless-steel beaker was used, cleaned, and kept in an oven at test temperature with the asphalt binder. The beaker was put on a hot plate to maintain a constant mixing temperature; a mixer running at $500 \mathrm{rpm}$ was then used. An amount of filler preheated to $150^{\circ} \mathrm{C}$, in compliance with each of the three mentioned filler-to-bitumen study ratios, was gradually added to the beaker while stirring; the mixing process lasted for at least 30 minutes, until a homogenous binder-filler mastic was obtained (Figure 3).

In the case of cold mastics (Figure 3), the bituminous emulsion and filler were put into two different boxes and heated in an oven to $60^{\circ} \mathrm{C}$ according to the technical workability specification of the bituminous emulsion, until homogenous conditioning was reached.

The mixing process was different from that adopted for the hot mastics. An initial water content hypothesis was assumed for a suitable mastic workability level in compliance with UNI EN 1744-1; consequently, a filler-towater content per mass of $0.5(f / W=0.5)$ was used for all three study filler-to-extracted bitumen (0.3, 0.4, and $0.5)$ ratios. Table 3 shows the minimum quantity of water for each mastic, which was guaranteed by varying the 


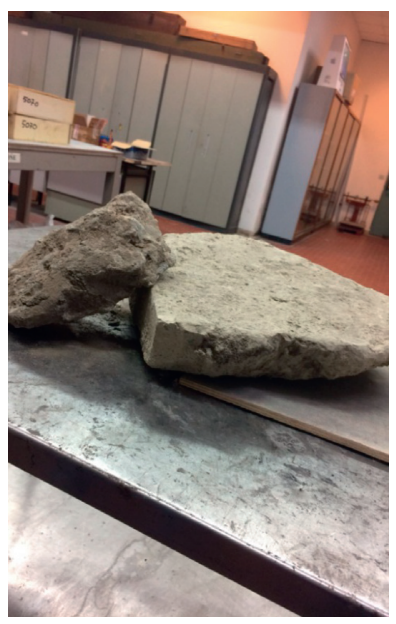

(a)

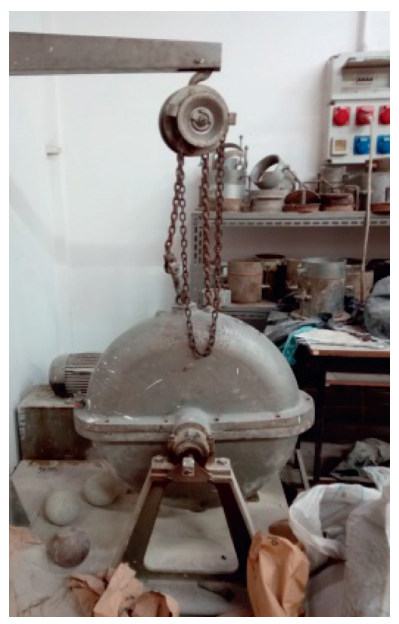

(b)

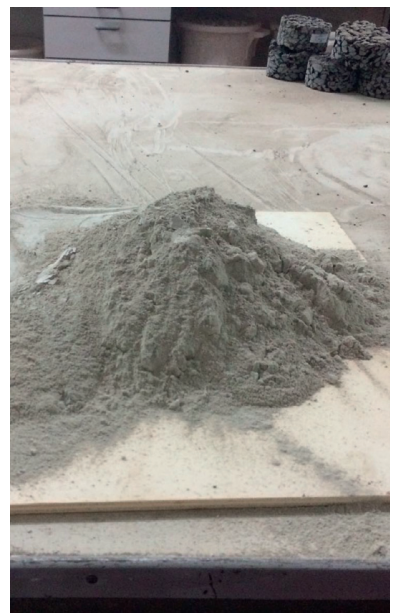

(c)

FIGURE 2: Jet grouting waste before and after the grinding process. (a) Before grinding. (b) Grinding device. (c) After grinding.

TABLE 2: Binder properties: (a) neat bitumen 50/70, (b) bituminous emulsion 60/40, and (c) bitumen contained in bituminous emulsion.

\begin{tabular}{|c|c|c|c|}
\hline Properties & Unit & Standard & Value \\
\hline \multicolumn{4}{|l|}{ (a) } \\
\hline Penetration at $25^{\circ} \mathrm{C}$ & $\mathrm{dmm}$ & UNI EN 1426 & 64 \\
\hline Softening point (R\&B) & ${ }^{\circ} \mathrm{C}$ & UNI EN 1427 & 46 \\
\hline Dynamic viscosity at $150^{\circ} \mathrm{C}$ & & & 0.25 \\
\hline Dynamic viscosity at $135^{\circ} \mathrm{C}$ & $\mathrm{Pa} \mathrm{s}$ & UNI EN 13702 & 0.413 \\
\hline Dynamic viscosity at $60^{\circ} \mathrm{C}$ & & & 3.220 \\
\hline Fraass & ${ }^{\circ} \mathrm{C}$ & UNI EN 12593 & -9 \\
\hline Characteristics & Unit & Value & Standard \\
\hline \multicolumn{4}{|l|}{ (b) } \\
\hline Water content & $\%$ & 40 & UNI EN 1428 \\
\hline $\mathrm{pH}$ value & - & 4.2 & UNI EN 12850 \\
\hline Settling tendency at 7 days & $\%$ & 5.8 & UNI EN 12847 \\
\hline Properties & Unit & Standard & Value \\
\hline \multicolumn{4}{|l|}{ (c) } \\
\hline Penetration at $25^{\circ} \mathrm{C}$ & $\mathrm{dmm}$ & UNI EN 1426 & 62 \\
\hline Softening point (R\&B) & ${ }^{\circ} \mathrm{C}$ & UNI EN 1427 & 47 \\
\hline
\end{tabular}

filler type and according to the three abovementioned ratios.

For only the cold mastics containing LF or JW filler, the bituminous emulsion broke up within 15 minutes after adding filler with water (see amount of mastic mixing per 100 gr of the study sample in Table 3). 15 minutes were long enough to allow the separation of the bituminous emulsion into water and bitumen.

On the contrary, for mastics made from LF plus JW filler added to BE previously mixed with a suitable amount of water to obtain workability, the BE broke up at the close of the 24th hour.

The water remaining from the separation of the water and bitumen was removed, and the cold mastic obtained was subsequently subjected to a $72 \mathrm{~h}$ conditioning process in the oven at $60^{\circ} \mathrm{C}$ until the remaining water was fully expelled.

A comparison of bitumen produced from bituminous emulsion after conditioning in the oven for $72 \mathrm{~h}$ at $60^{\circ} \mathrm{C}$ and aged bitumen made from bituminous emulsion using a rolling thin film oven (RTFO) procedure (Figure 4) has shown that the values of the latter, in terms of softening point and penetration grade at $25^{\circ} \mathrm{C}$, are not comparable to the previous one as they are higher (Table 4); the conditioning process was therefore such that it did not cause aging of the bitumen contained in the cold mastics.

After the conditioning process, the actual filler content for each of the 18 mastics was checked.

Ten grams of mastic were poured into glass test tubes, and a suitable quantity of "perchloroethylene" was added to submerge the mastic; the sample was stirred for ten minutes (Figure 5). Centrifugation was performed on four samples at the same time to verify the repeatability of the results achieved; the four samples (mastic plus perchloroethylene) reached the same weight. In fact, before inserting the four glass test tubes into the centrifuge, the correct balance of sample quantities (mastic plus solvent) was checked to avoid imbalance during centrifugation. Centrifugation lasted 30 minutes at a speed of 6,000 revolutions/minute. At the end of the centrifuge process, the solvent was removed using a filter paper to help retain filler particles. To remove all quantities 


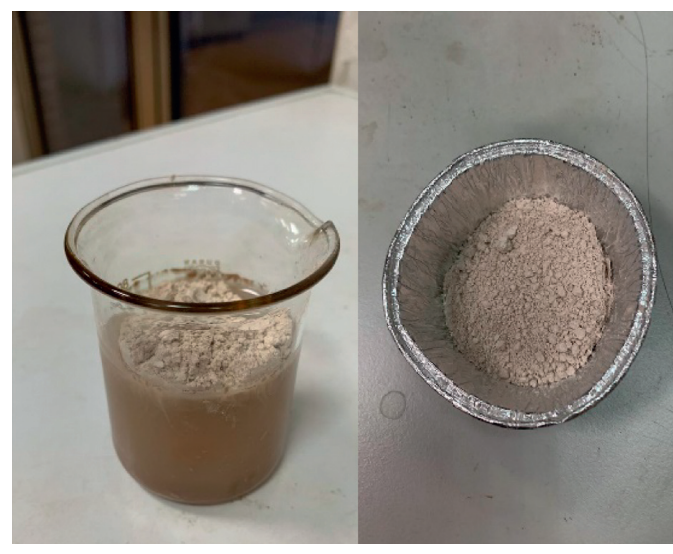

(A)
(B)

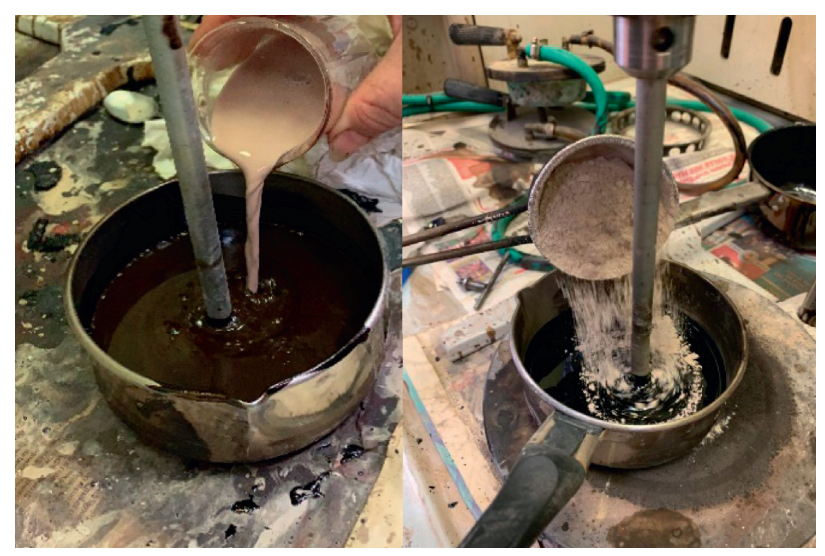

(A)

(B)

(a)

(b)

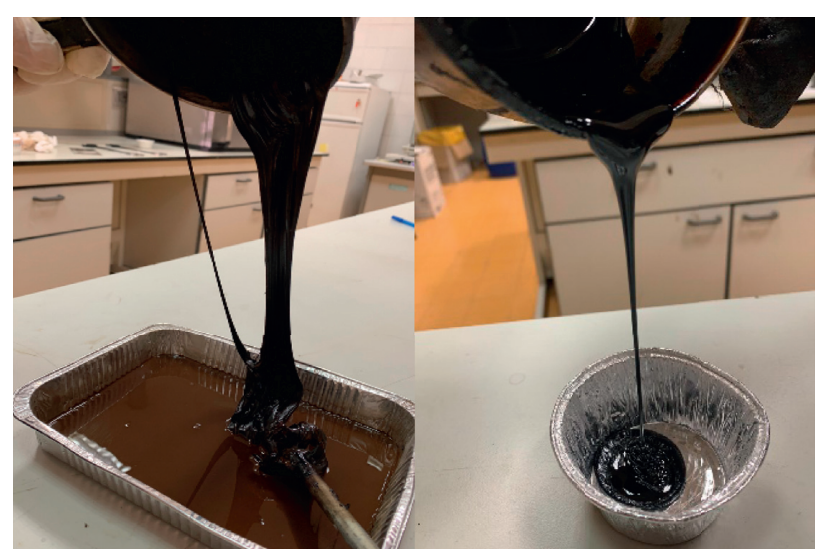

(A)

(B)

(c)

Figure 3: Mastic preparation using jet grouting waste. (a) Filler preparation: (A) cold mastic and (B) hot mastic. (b) Adding filler to the binder: (A) cold mastic and (B) hot mastic. (c) Final mastic: (A) cold mastic and (B) hot mastic.

TABle 3: Amount of mastic mixing materials per $100 \mathrm{gr}$ of the study sample.

\begin{tabular}{|c|c|c|c|c|c|c|c|}
\hline \multirow[b]{2}{*}{ Type } & \multirow[b]{2}{*}{$\begin{array}{l}\text { Filler-to-bitumen } \\
\quad \text { ratio }(\%)\end{array}$} & \multirow[b]{2}{*}{ Label } & \multicolumn{5}{|c|}{ Materials (gr) } \\
\hline & & & $\mathrm{LF}$ & JW & $\begin{array}{c}\text { Water } f / W=0.5 \\
\text { (added }+ \text { contained in } \mathrm{BE})\end{array}$ & $\mathrm{B} 50 / 70$ & $\begin{array}{c}\mathrm{BE} \\
(60 \% \text { bitumen }+40 \% \text { water })\end{array}$ \\
\hline \multirow{9}{*}{$\begin{array}{l}\text { Hot } \\
\text { mastics }\end{array}$} & \multirow{3}{*}{0.3} & $\mathrm{LH}_{0.3}$ & 30 & - & - & 70 & - \\
\hline & & $\mathrm{JH}_{0.3}$ & - & 30 & - & 70 & - \\
\hline & & $\mathrm{LJH}_{0.3}$ & 15 & 15 & - & 70 & - \\
\hline & \multirow{3}{*}{0.4} & $\mathrm{LH}_{0.4}$ & 40 & - & - & 60 & - \\
\hline & & $\mathrm{JH}_{0.4}$ & - & 40 & - & 60 & - \\
\hline & & $\mathrm{LJH}_{0.4}$ & 20 & 20 & - & 60 & - \\
\hline & \multirow{3}{*}{0.5} & $\mathrm{LH}_{0.5}$ & 50 & - & - & 50 & - \\
\hline & & $\mathrm{JH}_{0.5}$ & - & 50 & - & 50 & - \\
\hline & & $\mathrm{LJH}_{0.5}$ & 25 & 25 & - & 50 & - \\
\hline \multirow{9}{*}{$\begin{array}{l}\text { Cold } \\
\text { mastics }\end{array}$} & \multirow{3}{*}{0.3} & $\mathrm{LC}_{0.3}$ & 30 & - & 60 (13.2 added +46.8 contained in $\mathrm{BE})$ & - & 117 (70.2 bitumen +46.8 water $)$ \\
\hline & & $\mathrm{JC}_{0.3}$ & - & 30 & $60(13.2$ added +46.8 contained in $\mathrm{BE})$ & - & 117 (70.2 bitumen +46.8 water $)$ \\
\hline & & $\mathrm{LJC}_{0.3}$ & 15 & 15 & 60 (13.2 added +46.8 contained in $\mathrm{BE})$ & - & 117 (70.2 bitumen +46.8 water $)$ \\
\hline & \multirow{3}{*}{0.4} & $\mathrm{LC}_{0.4}$ & 40 & - & 80 (40 added +40 contained in $\mathrm{BE}$ ) & - & 100 (60 bitumen +40 water $)$ \\
\hline & & $\mathrm{JC}_{0.4}$ & - & 40 & 80 (40 added +40 contained in $\mathrm{BE})$ & - & 100 (60 bitumen +40 water $)$ \\
\hline & & $\mathrm{LJC}_{0.4}$ & 20 & 20 & 80 (40 added +40 contained in $\mathrm{BE})$ & - & 100 (60 bitumen +40 water $)$ \\
\hline & \multirow{3}{*}{0.5} & $\mathrm{LC} 0.5$ & 50 & & $100(66.8$ added +33.2 contained in $\mathrm{BE})$ & - & 83 (49.8 bitumen +33.2 water $)$ \\
\hline & & $\mathrm{JC} 0.5$ & & 50 & $100(66.8$ added +33.2 contained in $\mathrm{BE})$ & - & 83 (49.8 bitumen +33.2 water $)$ \\
\hline & & LJC0.5 & 25 & 25 & $100(66.8$ added +33.2 contained in $\mathrm{BE})$ & - & 83 (49.8 bitumen +33.2 water) \\
\hline
\end{tabular}




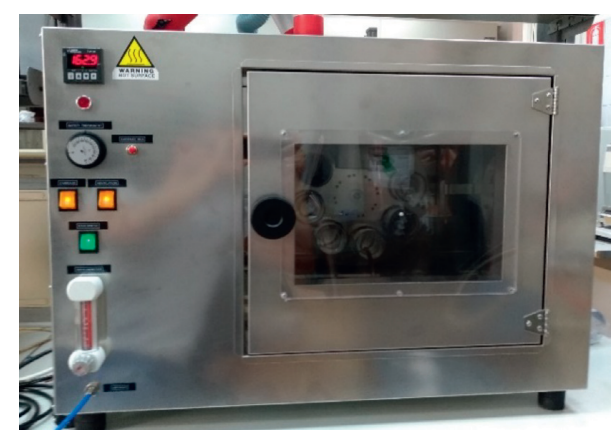

Figure 4: RTFO device.

TABLE 4: Bitumen from EB 60/40 properties after aging and curing.

\begin{tabular}{lcccc}
\hline Properties & Unit & Standard & $\begin{array}{c}\text { Aged bitumen } \\
\text { from EB60/40 }\end{array}$ & $\begin{array}{c}\text { Bitumen } \\
\text { from EB60/40 } \\
\text { after } 72 \mathrm{~h} \text { at } \\
60^{\circ} \mathrm{C}\end{array}$ \\
\hline $\begin{array}{l}\text { Penetration } \\
\text { at } 25^{\circ} \mathrm{C}\end{array}$ & $\mathrm{dmm}$ & $\begin{array}{c}\text { UNI EN } \\
1426\end{array}$ & 40 & 60 \\
$\begin{array}{l}\text { Softening } \\
\text { point }(\mathrm{R} \& \mathrm{~B})\end{array}$ & ${ }^{\circ} \mathrm{C}$ & $\begin{array}{c}\mathrm{UNI} \mathrm{EN} \\
1427\end{array}$ & 54.5 & 49 \\
\hline
\end{tabular}

of solvent, the filter papers and each glass test tube were put in an oven heated to above the boiling temperature of the solvent for a maximum of around one hour to reach a constant weight. The amount of residual filler and, therefore, its ratio to bitumen are expressed in the following equation:

$$
\frac{f}{b}=\frac{P_{2}-P_{3}}{P_{3}-P_{1}},
$$

where $f / b$ is the actual ratio of the mastic being tested; $P_{1}$ is the weight of the glass test tubes, in grams; $P_{2}$ is the weight of the glass test tubes plus the quantity of mastic before centrifuge, in grams; and $P_{3}$ is the weight of the glass test tubes with the residual amount of filler after the curing process, in grams.

The results in Table 5 show that, in the case of hot mastics, the amount of filler obtained following the abovementioned procedure is the same as that adopted in the first phase of mastic preparation and no change in the filler-to-bitumen ratio was observed before and after centrifugation.

On the contrary, a loss of filler was observed when cold mastic was prepared with filler-to-bitumen ratios of 0.4 and 0.5 after centrifugation for all the filler types adopted here. Consequently, the ratios of 0.4 and 0.5 were not investigated further as the mixture is chemically unstable and produces insufficient adhesion for the solution proposed here. Consequently, only a filler-to-bitumen ratio of 0.3 was examined further, as it satisfies the test proposed here due to the component materials adopted, and will therefore be simply labelled LC (LF added to EB), JC (JW added to EB), and LJC (LF plus JW added to EB) in the rest of this paper.

2.3. Methods. The bituminous binder has extremely varied mechanical behaviour that ranges from a typical elastic solid at low temperatures to that of a Newtonian-type viscous fluid at high ones. These boundary conditions include intermediate viscoelastic stages, i.e., characterized by the simultaneous presence of elastic and viscous phases. The elastic and viscous responses make the material time dependent. Reactions to traffic and environmental conditions can be observed through its rheological properties, clearly connected to the performance of an asphalt binder such as shear modulus $G^{*}$ and nonrecoverable creep compliance $J_{\mathrm{nr}}$.

2.3.1. Frequency Sweep Test. An “Anton Paar" dynamic shear rheometer (DSR) (Figure 6) was used to analyze the dynamic mechanical properties of bitumen and the stiffening effect connected to the addition of two fillers: mineral filler (LF) and alternative filler (JW), which were adopted to mix mastics.

The complex shear modulus $G^{*}$ is calculated as follows:

$$
\begin{aligned}
G^{*} & =\frac{\tau_{\max }}{\gamma_{\max }}, \\
\tau_{\max } & =\frac{T \cdot r}{I},
\end{aligned}
$$

where $\tau_{\text {max }}$ is the maximum value of the shear stress, $T$ is the maximum torque applied, and $I=\int_{0}^{r} u^{2} \mathrm{~d} A=$ moment of inertia, where $u$ is the speed of the torque and $r$ is the radius of the specimen (either 12.5 or $4 \mathrm{~mm}$ ):

$$
\gamma=\frac{u}{h} \theta \longrightarrow \gamma_{\max }=\frac{r}{h} \theta
$$

where $\gamma$ is the shear strain, $h$ is the specimen height (either 1 or $2 \mathrm{~mm}), \gamma_{\max }$ is the maximum value of the shear strain, and $\theta$ is the rotation angle.

The test at the selected temperatures starts at the highest frequency and moves to the lowest falling within the LVE region. In this context, it is important to investigate the LVE properties in order to understand how the proportion of each filler type can affect the entire LVE behaviour of the associated mixture. Different proportions generating various microstructures can produce a wide range of bituminous material behaviours [11].

An FS test was conducted at a range of frequencies between 0.01 and $10 \mathrm{~Hz}$, at temperatures of 10, 20, 30, 40, 50, and $60^{\circ} \mathrm{C}$. An $8 \mathrm{~mm}$ plate with a $2 \mathrm{~mm}$ gap was used below $30^{\circ} \mathrm{C}$, and above this temperature, a $25 \mathrm{~mm}$ plate and a $1 \mathrm{~mm}$ gap were used. In the FS test, the complex shear modulus $\left(G^{*}\right)$ was measured and analyzed from the point of view of master curves. [12].

Master curves were then plotted using the time-temperature superposition principle by shifting the modulus data at various temperatures with respect to frequency until the curves merged into a single function of the modulus in relation to the reduced frequency. The shift factor $a(T)$ is the amount of shift required to form the master curve at each temperature.

The shift factor depends on the nature of the material and should therefore be assessed experimentally. The common equation used take the name of the Williams-Landel-Ferry law is as follows: 


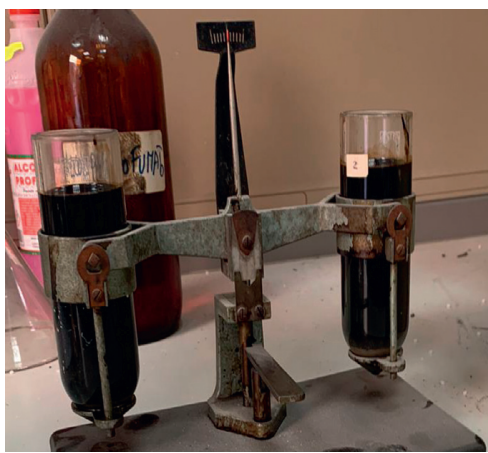

(a)

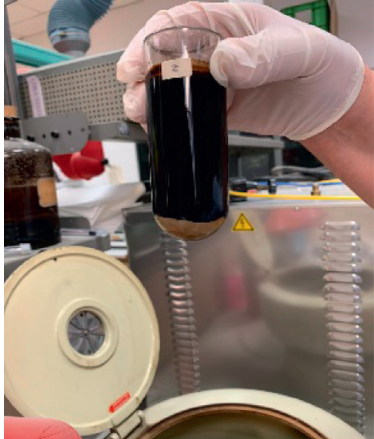

(b)

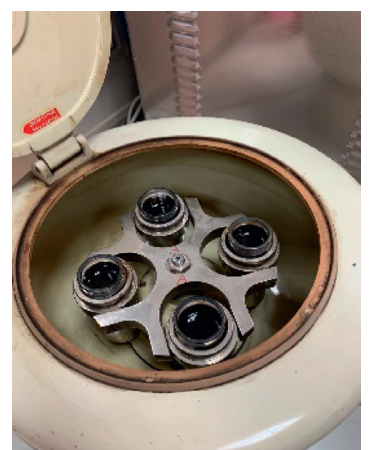

(c)

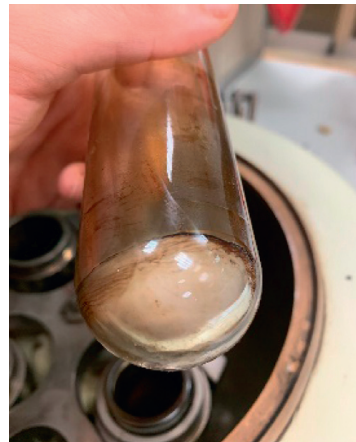

(d)

FIGURE 5: Checking filler content: (a) calibration of the glass test tubes, (b) specimen ready for the centrifuge, (c) centrifuge equipment, and (d) residual filler.

TABLE 5: Filler-to-bitumen ratio results.

\begin{tabular}{|c|c|c|c|c|c|c|c|}
\hline \multicolumn{8}{|c|}{ Hot mastics } \\
\hline \multirow{2}{*}{$f / b$} & \multirow{2}{*}{ Weight } & \multicolumn{2}{|c|}{$\mathrm{LH}$} & \multicolumn{2}{|c|}{$\mathrm{JH}$} & \multicolumn{2}{|c|}{$\mathrm{LJH}$} \\
\hline & & Specimen 1 & Specimen 2 & Specimen 1 & Specimen 2 & Specimen 1 & Specimen 2 \\
\hline \multirow{4}{*}{0.3} & $\mathrm{P} 1$ & 112.230 & 115.880 & 135.970 & 126.160 & 112.200 & 115.830 \\
\hline & $\mathrm{P} 2$ & 122.260 & 126.000 & 145.990 & 136.190 & 122.200 & 125.860 \\
\hline & P3 & 114.480 & 118.105 & 138.279 & 128.469 & 114.450 & 118.121 \\
\hline & $f / b$ & 0.289 & 0.282 & 0.299 & 0.299 & 0.290 & 0.296 \\
\hline \multirow{4}{*}{0.4} & $\mathrm{P} 1$ & 112.210 & 115.830 & 135.930 & 126.120 & 112.200 & 115.880 \\
\hline & $\mathrm{P} 2$ & 122.210 & 226.780 & 145.930 & 137.120 & 122.900 & 125.880 \\
\hline & P3 & 115.036 & 147.530 & 138.739 & 129.183 & 115.259 & 118.726 \\
\hline & $f / b$ & 0.394 & 0.400 & 0.391 & 0.386 & 0.400 & 0.398 \\
\hline \multirow{4}{*}{0.5} & $\mathrm{P} 1$ & 112.230 & 115.860 & 135.910 & 126.150 & 112.180 & 115.860 \\
\hline & $\mathrm{P} 2$ & 122.430 & 125.960 & 145.910 & 136.350 & 122.580 & 125.860 \\
\hline & P3 & 115.627 & 119.163 & 139.243 & 129.486 & 115.627 & 119.153 \\
\hline & $f / b$ & 0.499 & 0.486 & 0.500 & 0.486 & 0.496 & 0.491 \\
\hline \multirow{3}{*}{$f / b$} & & \multirow{2}{*}{\multicolumn{4}{|c|}{ Cold mastics }} & \multirow{2}{*}{\multicolumn{2}{|c|}{ LJC }} \\
\hline & Weight & & & & & & \\
\hline & W eignt & Specimen 1 & Specimen 2 & Specimen 1 & Specimen 2 & Specimen 1 & Specimen 2 \\
\hline \multirow{4}{*}{0.3} & $\mathrm{P} 1$ & 136.000 & 126.120 & 112.220 & 115.880 & 135.990 & 126.150 \\
\hline & $\mathrm{P} 2$ & 146.100 & 136.120 & 122.230 & 125.900 & 146.100 & 136.140 \\
\hline & P3 & 138.331 & 128.412 & 114.520 & 118.000 & 138.302 & 128.455 \\
\hline & $f / b$ & 0.300 & 0.297 & 0.298 & 0.268 & 0.296 & 0.300 \\
\hline \multirow{4}{*}{0.4} & $\mathrm{P} 1$ & 135.980 & 126.160 & 112.210 & 115.870 & 135.960 & 126.110 \\
\hline & $\mathrm{P} 2$ & 146.680 & 136.260 & 122.210 & 125.990 & 146.160 & 136.130 \\
\hline & P3 & 138.584 & 128.754 & 114.719 & 118.332 & 138.490 & 128.497 \\
\hline & $\mathrm{f} / \mathrm{b}$ & 0.322 & 0.346 & 0.335 & 0.322 & 0.330 & 0.313 \\
\hline \multirow{4}{*}{0.5} & $\mathrm{P} 1$ & 135.000 & 126.110 & 112.230 & 115.880 & 135.970 & 126.130 \\
\hline & $\mathrm{P} 2$ & 145.100 & 136.110 & 122.390 & 126.150 & 146.330 & 136.330 \\
\hline & P3 & 137.613 & 128.753 & 114.845 & 118.371 & 138.710 & 128.620 \\
\hline & $\mathrm{f} / \mathrm{b}$ & 0.349 & 0.359 & 0.347 & 0.320 & 0.360 & 0.323 \\
\hline
\end{tabular}

$$
\log \frac{a(T)}{a\left(T_{0}\right)}=\frac{-C_{1} \cdot\left(T-T_{0}\right)}{C_{2}+T-T_{0}},
$$

where $a(T)$ and $a\left(T_{0}\right)$ are the shift factors at temperatures $T$ and $T_{0}, T$ is the shift temperature, $T_{0}$ is the temperature of reference for the shift, and $C_{1}$ and $C_{2}$ are the constants that depend on the nature of the material.

2.3.2. Multistress Creep and Recovery Test. To assess bituminous binders at high service temperatures, and especially to evaluate stress or loading resistance [13], the MSCR test was performed in accordance with UNI EN 16659.

Nonrecoverable creep compliance $J_{\mathrm{nr}}$ is an indicator of the resistance of bitumen and bituminous mastics to permanent deformation under repeated load.

The test was performed at 40 and $60^{\circ} \mathrm{C}$ in light of the main results from the FS test where the $25 \mathrm{~mm}$ parallel plate geometry was used with a $1 \mathrm{~mm}$ gap setting. The test consists of an initial loading phase kept constant for one second, followed by a recovery phase of nine seconds; ten creep and 


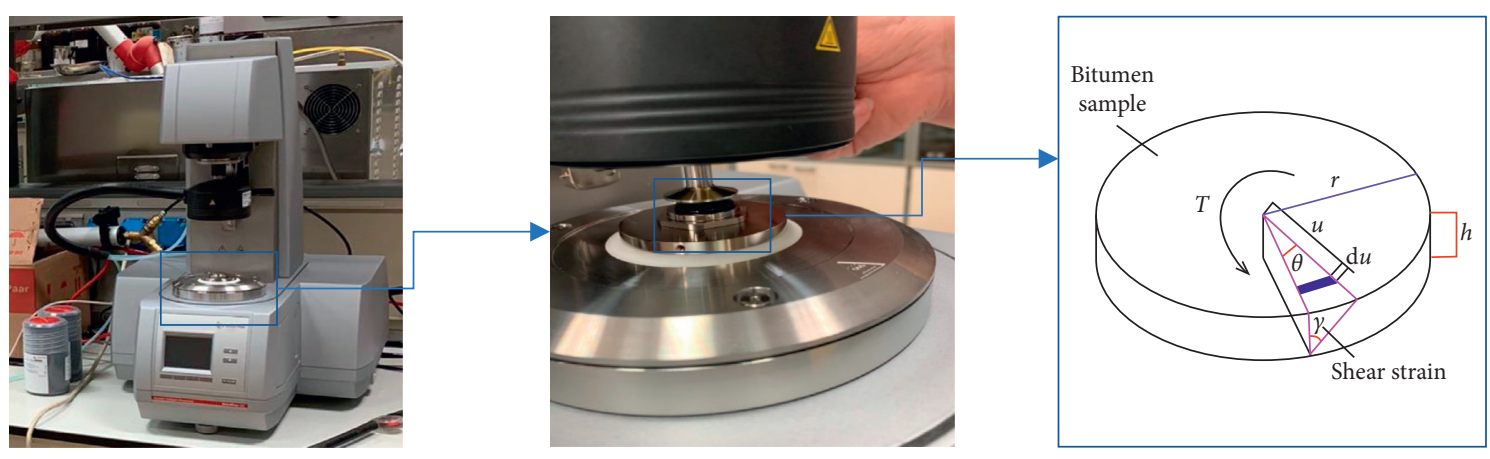

Figure 6: The dynamic shear rheometer used for investigating rheological properties.

recovery cycles are run at $0.100 \mathrm{kPa}$ creep stress followed by ten more cycles at $3.200 \mathrm{kPa}$ creep stress.

MSCR results show that adding filler leads to reduced susceptibility, to permanent deformation, and an enhanced elastic response depending on the combination of filler types [14].

The results obtained from the MSCR test are expressed as follows:

(i) $J_{\text {nr }}$, nonrecoverable creep compliance, calculated by dividing the residual strain postrecovery phase by the stress applied during creep loading

(ii) $\bar{J}_{n r}$, the average nonrecoverable creep compliance, calculated as the mean of $10 J_{\mathrm{nr}}$ values

(iii) $\bar{J}_{\mathrm{nr}}$ and $J_{\mathrm{TOT}}$, the ratio between the residual strain and accumulated strain at the end of the creep phase, where $J_{\text {TOT }}$ is evaluated immediately before load removal

(iv) $J_{\mathrm{nr}_{\text {ratio }}}$, the ratio between the average creep compliance $\left(\bar{J}_{\mathrm{nr}}\right)$ of the mastic containing alternative filler (LJH and LJC28d (cold mastic with LF and JW after 28 days curing time)) and the respective mastic containing limestone filler ( $\mathrm{LH}$ and LC28d (cold mastic with LF after 28 days curing time)) at the same stress level and test temperature

\section{Results}

3.1. Frequency Sweep Test. $G^{*}$ was taken as the rheological benchmark used to characterize and compare the nine mastics prepared by adopting a filler-to-bitumen ratio of 0.3 . Test temperatures were between $10^{\circ} \mathrm{C}$ and $60^{\circ} \mathrm{C}$ with an increment of $10^{\circ} \mathrm{C}$, and a test frequency ranges from 0.1 to $10 \mathrm{~Hz}$ across the 19 obtained measures. Strain amplitude sweep (SAS) tests were performed first with the aim of identifying the LVE limit and defining a suitable range of strain level for hot and cold mastics with all filler types. The SAS tests were performed at $10^{\circ} \mathrm{C}$ using $8 \mathrm{~mm}$ parallel plate geometry and a $2 \mathrm{~mm}$ gap, applying a constant frequency of $10 \mathrm{rad} / \mathrm{s}(1.59 \mathrm{~Hz})$. A unique strain level of $0.05 \%$ was adopted as the LVE limit for all mastics in order to simplify the testing procedure. This value was selected on the basis of the LVE limit identified for the LH mastic, although the other mastics had higher LVE limits [8, 15-17].
Figure 7 shows the master curves for the three hot mastics ((1) hot mastics made with LF filler added to B50/70, (2) hot mastics with JW filler added to B50/70, and (3) hot mastics with LF plus JW added to B50/70). It may be noted that adding the filler to the three hot mastics increases stiffness when compared to B50/70. In greater detail, LH returns the lowest $G^{*}$ values for all test temperatures and frequencies investigated compared to $\mathrm{JH}$ and $\mathrm{LJH}$; on the contrary, at a test temperature of $10^{\circ} \mathrm{C}, \mathrm{JH}$ behaves in a similar way to LH. It should also be noted that the highest $G^{*}$ values were observed for LJH; specifically, at a low test temperature, there were no great differences between $\mathrm{LH}$ and $\mathrm{JH}$, with behaviour very close to that of B50/70. Otherwise, at high temperatures, LJH gave higher $G^{*}$ performance than $\mathrm{LH}$ and B50/70, albeit quite close to that of $\mathrm{JH}$. The phase angle behaviour of mastics follows the base bitumen trend; neither filler changes the viscoelastic response of the bitumen, giving a completely viscous response at high temperatures and an elastic approach at low temperatures.

Before moving on to assess the cold mastics from the point of view of $G^{*}$ and $\delta$, an assessment of the behaviour of B50/70 in terms of $G^{*}$ and $\delta$ and the bitumen extracted (EB60/40) from the bituminous emulsion was carried out. Figure 8 shows the master curve results for the two bitumens, with no variation when moving from high to low test temperatures. Further clarification will be provided by the MSCR test in Section 3.3.

Three cold study mastics (LC, JC, and LJC) were prepared following the procedures shown in Section 2.2 and kept in an oven for 3 days at $60^{\circ} \mathrm{C}$ until a constant weight was reached. On the third day, no variation in weight had occurred, so after this period, three specimens of the cold mastics were tested for $G^{*}$ configuration according to the geometric configuration of the plates and gap shown in Section 2.3.1.

The master curves for the cold mastics are shown in Figure 9. What is immediately evident is the remarkable difference between the cold mastics after 3 days of curing time and the EB60/40 at low temperatures, where the former (LC, JC, and LJC) show lower $G^{*}$ values compared to EB60/ 40; on the contrary, JC reaches performance at temperatures up to $40^{\circ} \mathrm{C}$ and seems to produce the same behaviour as EB60/40. In comparison with the other two cold mastics at $10^{\circ} \mathrm{C}$, the LC shows a dramatic fall in $G^{*}$. In terms of the phase angle, it is possible to observe a lower $\delta$ value at high temperatures for LC than for EB60/40, with slightly elastic 


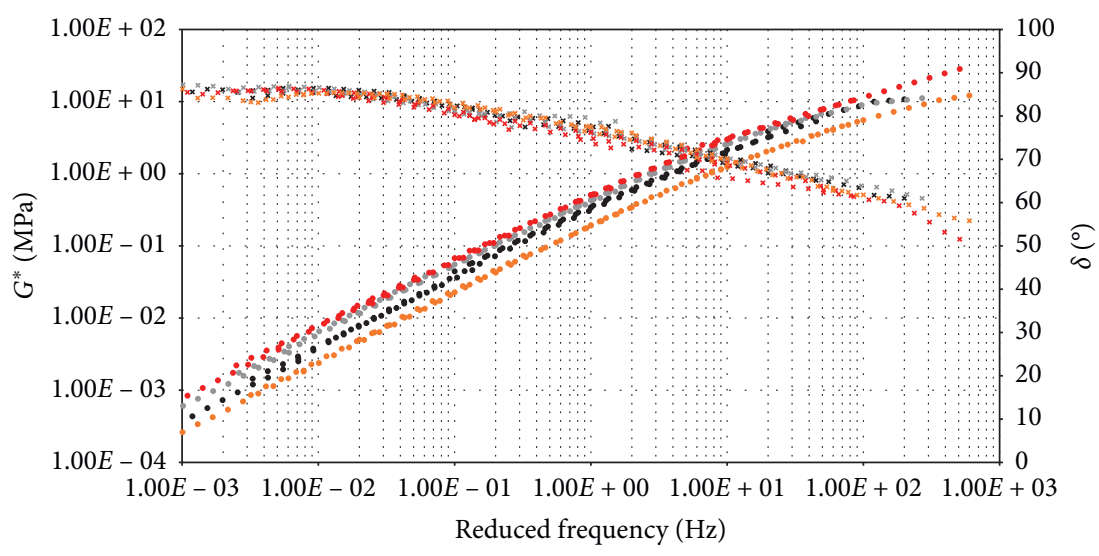
- $G^{*}{ } \mathrm{LH}$
- $G^{*} \_\mathrm{LJH}$
$\times \delta_{-} \mathrm{LH}$
$\times \delta \_\mathrm{LJH}$
- $G^{*}{ }_{-} \mathrm{JH}$
- $G^{*} \_B 50 / 70$
$\times \delta_{-} \mathrm{JH}$
$\times \delta \_\mathrm{B} 50 / 70$

FIGURE 7: Master curve for hot mastics and neat bitumen 50/70.

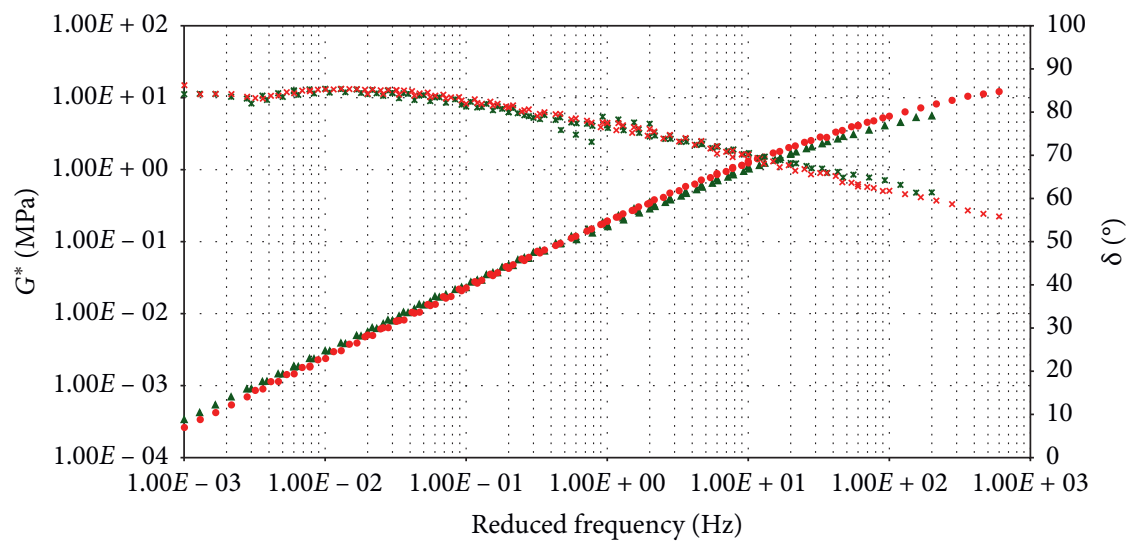

\ $G^{*}{ }_{-} \mathrm{EB} 60 / 40$

* $\delta \_\mathrm{EB} 60 / 40$

- $G^{*}{ }^{B} 50 / 70$

$\times \delta \_B 50 / 70$

Figure 8: Master curve of bitumen and bitumen vontained in emulsion.

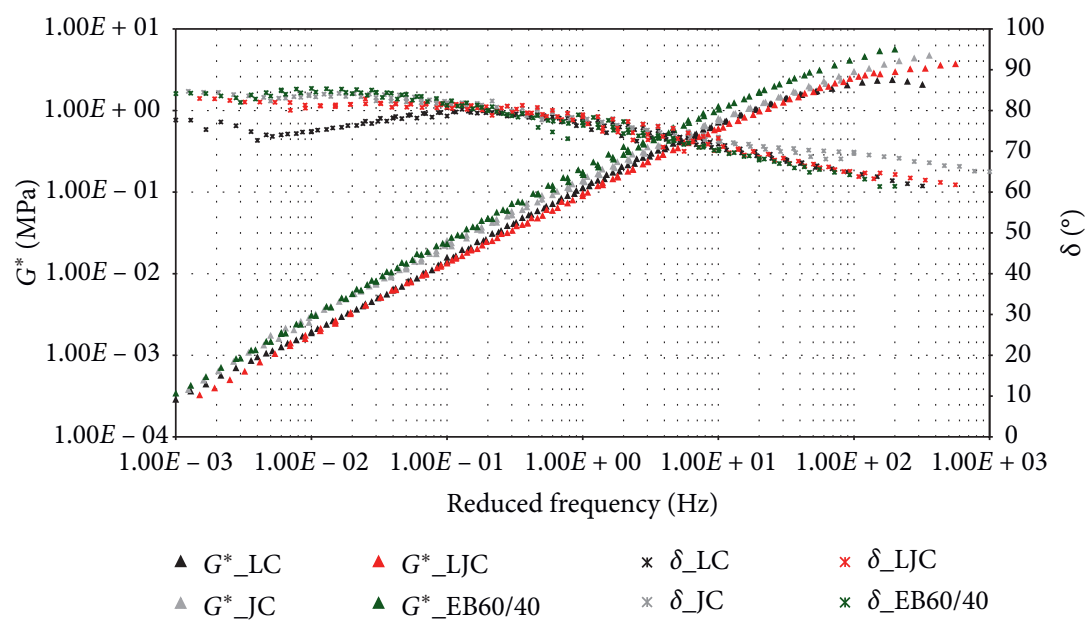

Figure 9: The master curves of the cold mastics after 3 days of curing time in an oven heated to $60^{\circ} \mathrm{C}$ and $\mathrm{EB} 60 / 40$. 
behaviour, which is the opposite of what happens at low temperatures, where the $\delta$ value for JC is higher than for EB60/40.

In particular, it can be observed that the trend of the phase angle at low temperatures for JC is the opposite of the trend for $G^{*}$ modulus; in this case, the behaviour of JC, unlike the other mastics, approaches that of a pseudoplastic material, which may mean that a mastic mix using only JW as a filler cannot increase the stiffness of bitumen after 3 days.

Since many studies carried out on CBM have demonstrated that maximum mechanical performance in terms of ITS and/or stiffness can be achieved on the 28th day of curing time [18], cold mastics that had been kept for 3 days at $60^{\circ} \mathrm{C}$ were subsequently kept at room temperature for 25 days (for a total of 28 days' curing time) and then subjected to $G^{*}$ evaluation (labelled LC28d (LF added to EB after 28 days of curing time), JC28d (JW added to EB after 28 days of curing time), and LJC28d (LF plus JW added to EB after 28 days of curing time).

The results of the FS test in terms of master curves are reported in Figure 10. Unlike the previous results for all cold mastics, $G^{*}$ always resulted higher than EB60/40, highlighting the stiffening effects of the fillers in the bitumen. In particular, it can be noted that, although JC28d $G^{*}$ is higher than EB60/40 at low temperatures $\left(10-20-30^{\circ} \mathrm{C}\right)$, JC28d is comparable to LC28d; on the contrary, at high temperatures (40-50-60 $\left.{ }^{\circ} \mathrm{C}\right)$, it displays worse behaviour with a reduction in $G^{*}$. When JW filler is added to the bitumen without LF, JC28d $G^{*}$ is lower than the remaining mastics. On the contrary, when JW is added to bitumen with LF, the $G^{*}$ value increases at all temperatures and for all frequency ranges (see LJC28d).

The phase angle behaviour of mastics follows the bituminous emulsion trend; in particular the LC28d $\delta$ values at higher temperatures resulted lower for all the mastics and the bituminous emulsion, while JC28d shows greater elasticity than the others at low temperatures. Furthermore, greater viscosity was observed when both LF and JW were added to bituminous emulsion.

Therefore, cold interaction between LF filler with bitumen favours the best mechanical performance of all the prepared mastics, including the hot ones (Figure 10).

On the basis of the results achieved so far, focusing only on the mastics that returned better performance during comparison when hot and cold procedures were used, it can be observed in Figure 11 that three main regions can be identified taking into account $G^{*}$ values: (1) for region I (test temperatures $>30^{\circ} \mathrm{C}$ ), it may be observed that LJC28d shows higher performance in terms of $G^{*}$ than LJH; (2) for region II (test temperatures from $20^{\circ} \mathrm{C}$ to $10^{\circ} \mathrm{C}$ ), LJC28d shows the same performance in relation to $G^{*}$ as $\mathrm{LJH}$; and (3) for region III (test temperatures $<10^{\circ} \mathrm{C}$ ), LJC28d displays poorer performance than $\mathrm{LJH}$, which, on the contrary, has a higher $G^{*}$.

3.2. MSCR Test. The passage of traffic loads generates stress within the pavement causing accumulated strain in the mixture. The rutting resistance of cold bituminous mixtures, like those of a traditional HMA, is due to (a) the interlocking of the aggregates and their form and (b) the stiffening effect of the mastic [19].

In the research presented here, mastic response to permanent deformation was estimated using the MSCR test. As the results shown in the previous sections demonstrated that best performance of cold mastics can be achieved at the end of the 28th day of curing time, the MSCR test was carried out using the abovementioned mastics and the hot mastics ( $\mathrm{LH}, \mathrm{JH}$, and $\mathrm{LJH}$ ) as control systems to measure the performance of the cold ones.

Table 6 shows $\bar{J}_{\mathrm{nr}}$, values for each of the six mastics $(\mathrm{LH}$, $\mathrm{JH}, \mathrm{LJH}, \mathrm{LC} 28 \mathrm{~d}, \mathrm{JC} 28 \mathrm{~d}$, and LJC28d) at temperature of $40^{\circ} \mathrm{C}$ and $60^{\circ} \mathrm{C}$ and $0.1 \mathrm{kPa}$ and $3.2 \mathrm{kPa}$ stress levels.

As expected, $\bar{J}_{\mathrm{nr}}$ increases as the temperature rises both for binders (B50/70 and EB60/40) and mastics. This is due to lower viscosity during the bituminous phase at higher temperatures, which results in higher permanent strain in the material under stress.

First of all, from a comparison between hot and cold mastics at the same test temperatures and load levels, all the cold mastics show a reduction of $\bar{J}_{\mathrm{nr}}$; in particular, at $40^{\circ} \mathrm{C}$ and at $3.2 \mathrm{kPa}$ stress level, a greater reduction was observed, comparing the cold mastics with the corresponding hot mastics, for LJC28d, associated with a $68 \% \bar{J}_{\mathrm{nr}}$ reduction compared with LJH; a reduction of $57 \%$ was observed moving from $\mathrm{LH}$ to $\mathrm{LC} 28 \mathrm{~d}$ and a $21 \% \bar{J}_{\mathrm{nr}}$ reduction when moving from $\mathrm{JH}$ to JC28d.

The experimental data highlight the contribution of adding alternative fillers to the bitumen and the bitumen derived from bituminous emulsion. The presence of JW improves the resistance of bitumen to permanent deformations, especially when added together with LF to bituminous binder. In fact, at temperatures of $40^{\circ} \mathrm{C}$ and $60^{\circ} \mathrm{C}$, when JW is added to B50/70 for hot packaging, the $\bar{J}_{\mathrm{nr}}$ values decrease by $38 \%$ and $21 \%$, respectively, compared with LH; as for the cold mastics, LJC28d returned the highest reduction compared with the remaining cold mastics. In particular, LJC28d is characterized by a $74 \% \bar{J}_{\mathrm{nr}}$ reduction at a $40^{\circ} \mathrm{C}$ test temperature and $52 \% \bar{J}_{\mathrm{nr}}$ at a $60^{\circ} \mathrm{C}$ test temperature compared to $\mathrm{LH}$.

Figure 12 shows the differences between hot and cold bituminous mastics in terms of accumulated strain during 10 creep and recovery cycles; when adding LF and JW to bitumen contained in bituminous emulsion (LJC28d), the stiffening effect reaches its highest value both at $40^{\circ} \mathrm{C}$ and $60^{\circ} \mathrm{C}$. This confirms the results obtained previously for $\bar{J}_{\mathrm{nr}}$.

The ability of each mastic to recover from deformation at the end of the creep phase was evaluated in terms of $J_{\mathrm{nr}} / J_{\mathrm{TOT}}$.

If the material is unable to recover from any deformation, and the strain measured at the end of the creep phase remains the same at the end of the recovery phase, $J_{\mathrm{nr}} / J_{\mathrm{TOT}}$ will be 1 . On the contrary, if the material is totally elastic and able to recover from all the accumulated deformation, $J_{\mathrm{nr}} / J_{\mathrm{TOT}}$ will be $0[14]$.

The results, in terms of $J_{\mathrm{nr}} / J_{\mathrm{TOT}}$ expressed as percentages, are reported in Figure 13 but only at a test temperature of $60^{\circ} \mathrm{C}$ and $3.2 \mathrm{kPa}$, as the results shown in Table 6 highlighted the most critical situations under these conditions. 


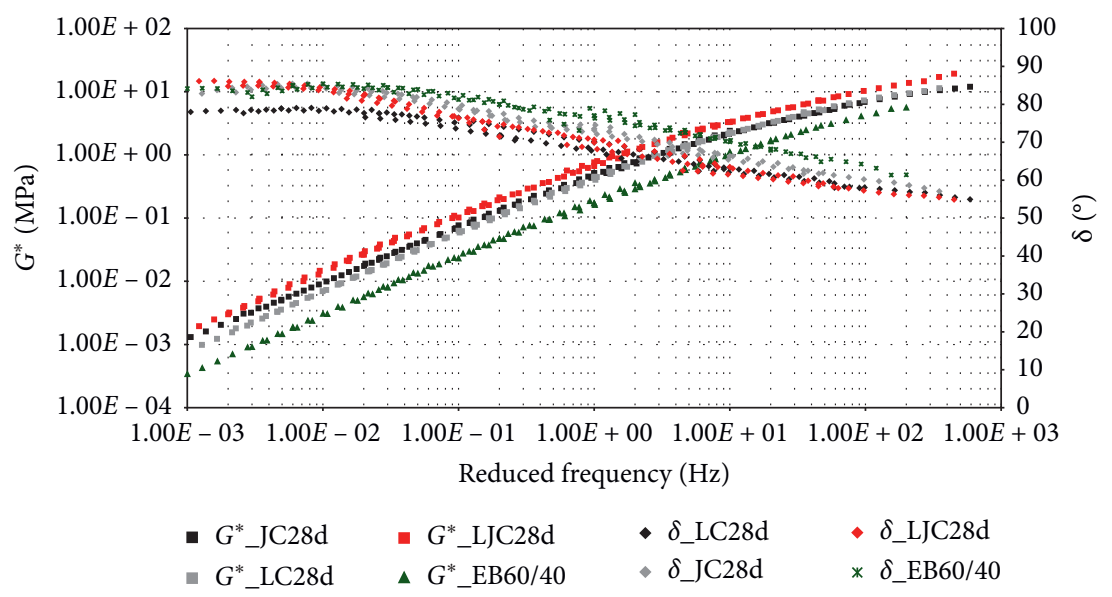

Figure 10: Master curves of the cold mastics subsequent to curing time, after being kept in the oven for three days at $60^{\circ} \mathrm{C}$ and at room temperature $\left(25^{\circ} \mathrm{C}\right)$ for 25 days.

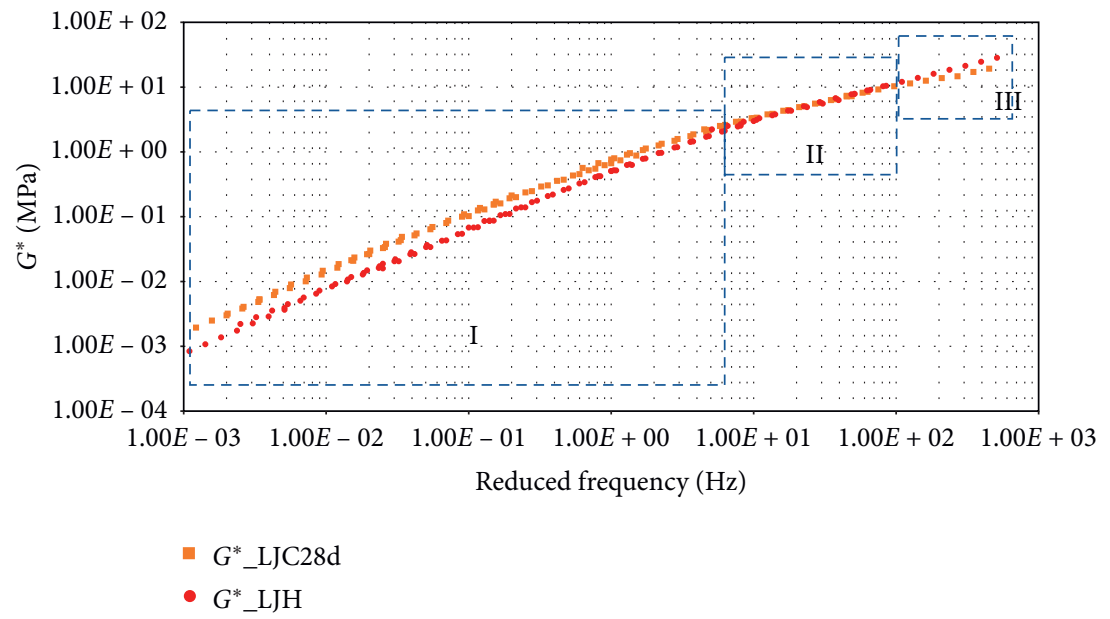

Figure 11: Master curves comparison between LJC28d and LJH.

TABLE 6: $\bar{J}_{\mathrm{nr}}$ value of hot and cold mastics.

\begin{tabular}{|c|c|c|c|c|c|}
\hline \multirow{3}{*}{ ID } & \multirow{3}{*}{ Specimens } & \multicolumn{4}{|c|}{ Test temperatures } \\
\hline & & \multicolumn{2}{|c|}{$40^{\circ} \mathrm{C}$} & \multicolumn{2}{|c|}{$60^{\circ} \mathrm{C}$} \\
\hline & & $J_{\mathrm{nr}-}-0.1 \mathrm{kPa}$ & $J_{\mathrm{nr}-} 3.2 \mathrm{kPa}$ & $J_{\mathrm{nr}-} 0.1 \mathrm{kPa}$ & $J_{\mathrm{nr}-}-3.2 \mathrm{kPa}$ \\
\hline 1 & B50/70 & 0.128 & 0.139 & 4.149 & 4.321 \\
\hline 2 & $\mathrm{~EB} 60 / 40$ & 0.112 & 0.128 & 3.387 & 3.829 \\
\hline 3 & $\mathrm{JH}$ & 0.083 & 0.091 & 2.312 & 2.503 \\
\hline 4 & JC28d & 0.053 & 0.062 & 2.059 & 2.211 \\
\hline 5 & LH & 0.137 & 0.143 & 3.002 & 3.054 \\
\hline 6 & LC28d & 0.051 & 0.072 & 1.767 & 2.394 \\
\hline 7 & LJH & 0.104 & 0.108 & 2.745 & 2.753 \\
\hline 8 & LJC28d & 0.036 & 0.052 & 1.360 & 1.529 \\
\hline
\end{tabular}

Table 7 shows that more than $30 \%$ of elastic deformation is recovered by LJC28d and positive performance was also observed for LC28d, which regains more than $25 \%$ of the deformation, while JC28d returns less than 25\% of elastic deformation. These results match previously achieved results in terms of $G^{*}$. Hot mastics have poorer performance in terms of recovery from elastic deformation when compared with cold mastics and, in all cases, less than the hot mastics.
JH shows the best performance (recovery of elastic deformation less than 15\%). This circumstance also confirms the results previously achieved in terms of $G^{*}$ for the cold mastics.

In order to further evaluate the stiffening effect of the JW when added to hot and cold bituminous mastics, a ratio between $\bar{J}_{\mathrm{nr}}$ for mastics containing JW with LF (as results for $G^{*}$ and $J_{\mathrm{nr}} / J_{\mathrm{TOT}}$ demonstrated how these mastics achieved the best performance) and $\bar{J}_{\mathrm{nr}}$ for mastics containing only LF, defined $J_{\mathrm{nr}_{\mathrm{ratio}}}$, was calculated from results in Table 6.

The results in Table 7 show that JW filler improves mastic stiffening during both hot and cold mixing. In particular, under hot conditions, the increase in stiffening caused by the addition of JW changes with the temperature but is not affected by stress levels. Under hot conditions, JW filler helps increase stiffening by almost $25 \%$ compared with $\mathrm{LH}$ mastic at a test temperature of $40^{\circ} \mathrm{C}$. In the case of hot mixing, the stiffening effect decreases from $40^{\circ} \mathrm{C}$ to $60^{\circ} \mathrm{C}$, making up only around $10 \%$ of a further increase in stiffness due to the presence of JW in the mastic. 


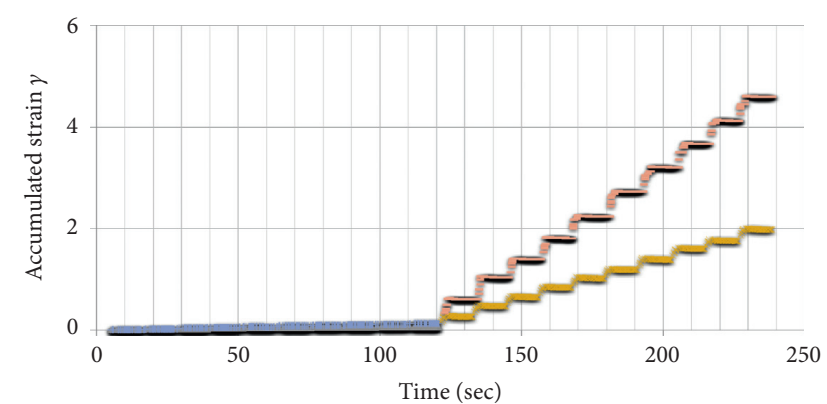

LC $28 \mathrm{~d} \_40^{\circ} \mathrm{C} \_0.1 \mathrm{kPa} \quad+$ LH_ $40^{\circ} \mathrm{C} \_0.1 \mathrm{kPa}$

LC $28 \mathrm{~d} \_40^{\circ} \mathrm{C} \_3.2 \mathrm{kPa} \quad-$ LH $\_40^{\circ} \mathrm{C} \_3.2 \mathrm{kPa}$

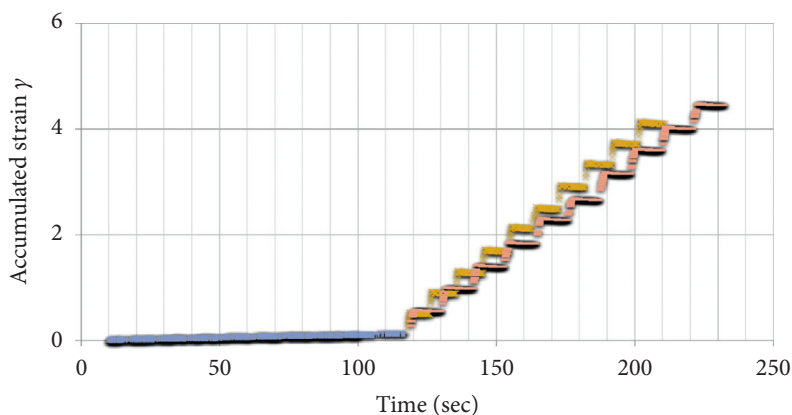

$\mathrm{EB} 60 / 40 \_40^{\circ} \_0.1 \mathrm{kPa} \quad+\mathrm{B} 50 / 70 \_40^{\circ} \_0.1 \mathrm{kPa}$ $\mathrm{EB} 60 / 40 \_40^{\circ} 3.2 \mathrm{kPa}$

B50/70_40 $3.2 \mathrm{kPa}$

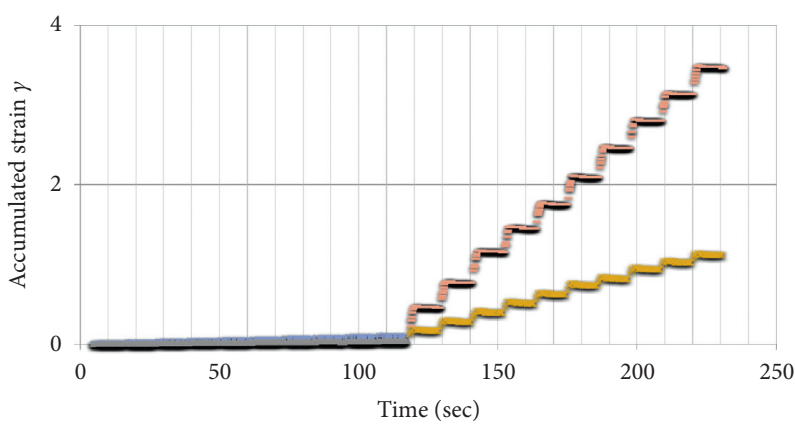

LJH_ $40^{\circ} \_0.1 \mathrm{kPa}$

LJH_40 $\_3.2 \mathrm{kPa}$
. LJC 28d_40 $20.1 \mathrm{kPa}$
$\times \quad$ LJC $28 \mathrm{~d} \_40^{\circ} \_3.2 \mathrm{kPa}$

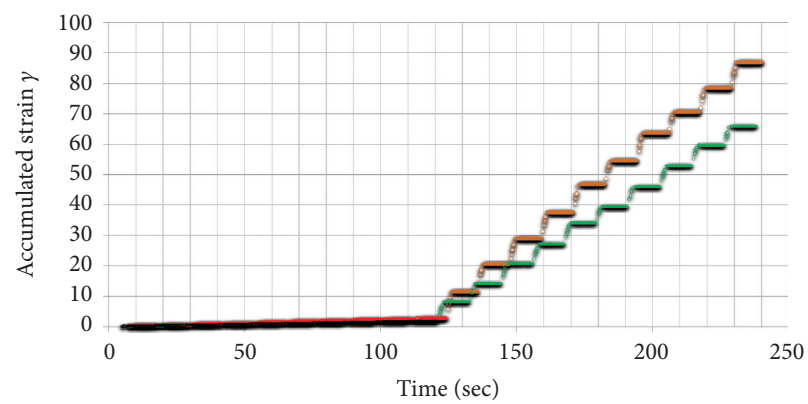

- LH_6 $60^{\circ} \mathrm{C} \_0.1 \mathrm{kPa} \quad$. LC2 $28 \mathrm{~d} \_60^{\circ} \mathrm{C} \_0.1 \mathrm{kPa}$

. $\mathrm{LH} \_60^{\circ} \mathrm{C} \_3.2 \mathrm{kPa} \quad$. LC $28 \mathrm{~d} \_60^{\circ} \mathrm{C} \_3.2 \mathrm{kPa}$

(a)

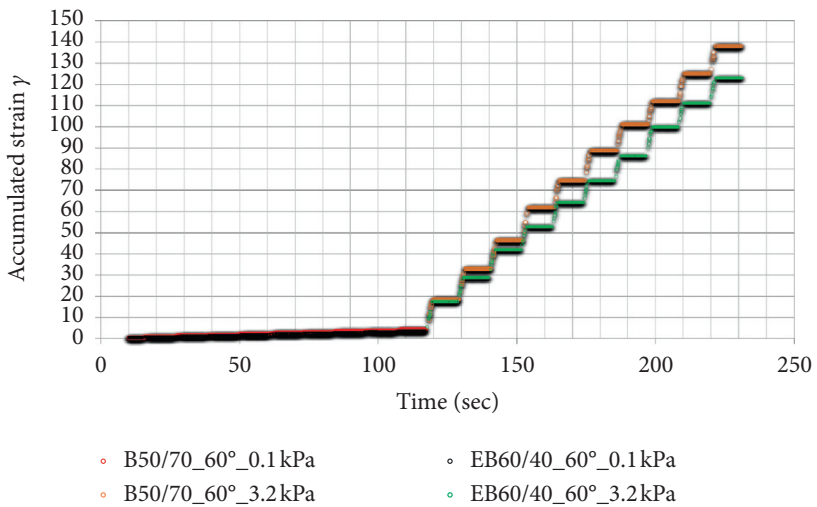

(b)

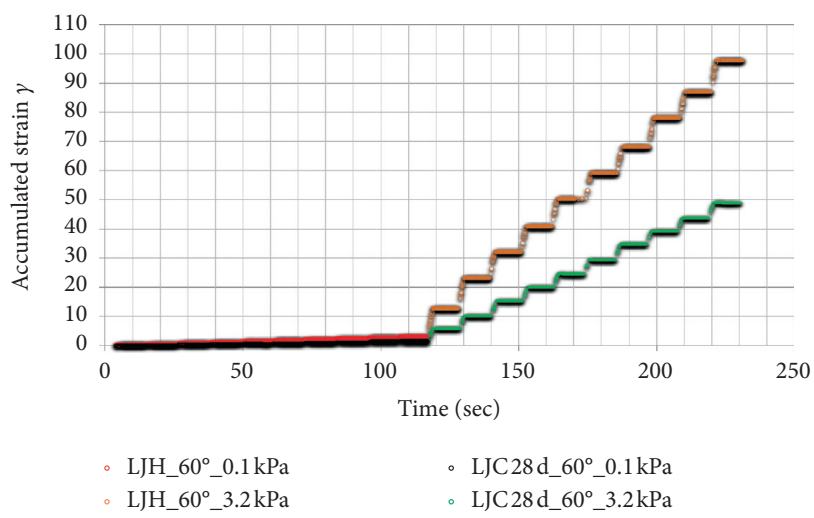

(c)

FIGURE 12: Accumulated strain results at the end of every 10 creep-recovery cycles of hot and cold bituminous mastics: (a) LH vs LC28d (I at $40^{\circ} \mathrm{C}$ and II at $60^{\circ} \mathrm{C}$ ), (b) JH vs JC28d (I at $40^{\circ} \mathrm{C}$ and II at $60^{\circ} \mathrm{C}$ ), and (c) LJH vs LJC28d (I at $40^{\circ} \mathrm{C}$ and II at $60^{\circ} \mathrm{C}$ ).

The greatest benefits can be achieved when the mastics are prepared under cold conditions: JW increases stiffness, both at $40^{\circ} \mathrm{C}$ and $60^{\circ} \mathrm{C}$. At 0.1 and $3.2 \mathrm{kPa}$, the increase is around $30 \%$ compared with cold mastic made up of limestone filler and bitumen.

\subsection{Mean Correlation Comparing Delta Ring and Ball and} $\bar{J}_{n r}$. The final test carried out was the most common $\Delta \mathrm{R} \& \mathrm{~B}$ (UNI EN 13179-1) assessment, measuring the difference between the R\&B of each mastic ( $\mathrm{LH}, \mathrm{JH}, \mathrm{LJH}, \mathrm{LC} 28 \mathrm{~d}$, JC28d, and LJC28d) and the R\&B of the binder adopted for mixing mastics (B50/70 and EB60/40) with a filler-tobitumen ratio of 0.3 (see Section 2.2 for more details).

Figure 14 shows the $\triangle \mathrm{R} \& \mathrm{~B}$ value for each mastic plotted as a function of two variables: the $x$-axis shows the study mastics (a total of six), while the $y$-axis shows the mean value of the stiffening increase produced by the addition of each filler to a mastic, compared with the binder, taking into account the effects produced at two test temperatures $\left(40^{\circ} \mathrm{C}\right.$ and $\left.60^{\circ} \mathrm{C}\right)$ and two stress levels $(0.1$ and $3.2 \mathrm{kPa})$. The last parameter is called $\bar{J}_{\text {temp,stress }}$ and can be calculated for each hot mastic using equation (5) and for each cold mastic using equation (6) as follows: 


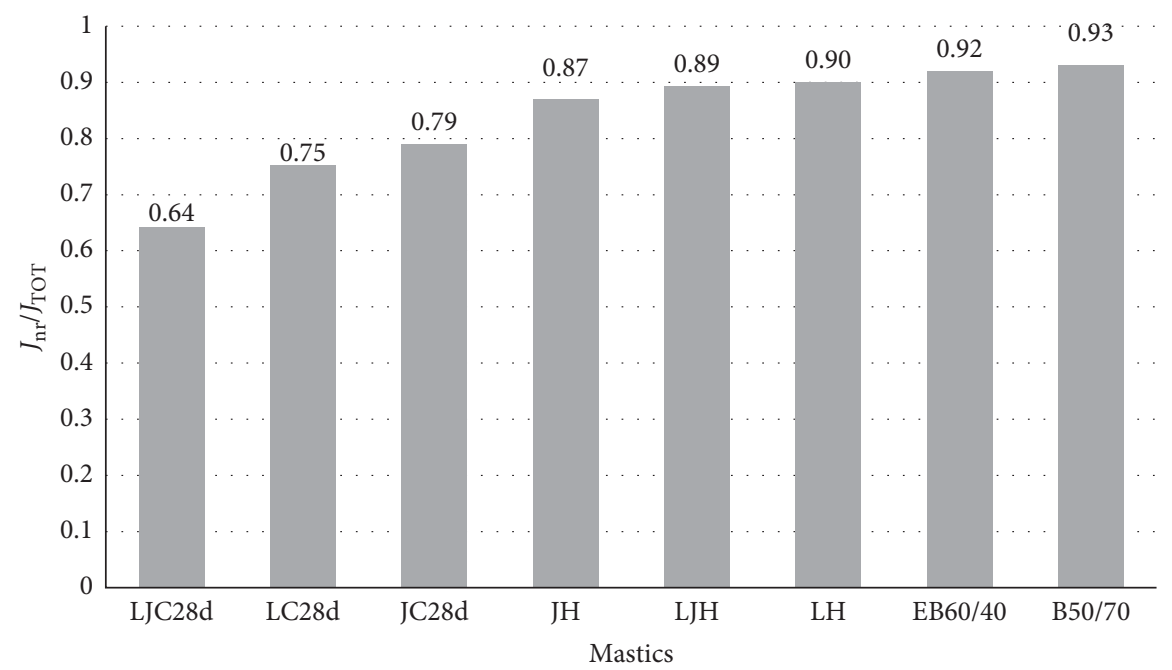

FIgURE 13: $J_{\text {nr }} / J_{\text {TOT }}$ results under $3.2 \mathrm{kPa}$ and $60^{\circ} \mathrm{C}$.

TABLE 7: $J_{\text {nr ratio }_{\text {rit }}}$ results: (a) LJH/LH and (b) LJC28d/LJ28d.

\begin{tabular}{|c|c|c|c|c|c|}
\hline \multirow{3}{*}{\multicolumn{2}{|c|}{ Mastics }} & \multicolumn{4}{|c|}{ Temperature } \\
\hline & & \multicolumn{2}{|c|}{$40^{\circ} \mathrm{C}$} & \multicolumn{2}{|c|}{$60^{\circ} \mathrm{C}$} \\
\hline & & $J_{\mathrm{nr}_{\mathrm{rati}}-}-0.1 \mathrm{kPa}$ & $J_{\mathrm{nr}_{\text {ratio }}-} 3.2 \mathrm{kPa}$ & $J_{\mathrm{nr}_{\mathrm{rati}}-} 0.1 \mathrm{kPa}$ & $J_{\mathrm{nr}_{\mathrm{rati}}-} 3.2 \mathrm{kPa}$ \\
\hline (a) & LJH & 0.763 & 0.755 & 0.914 & 0.901 \\
\hline (b) & LJC28d & 0.706 & 0.694 & 0.770 & 0.639 \\
\hline
\end{tabular}

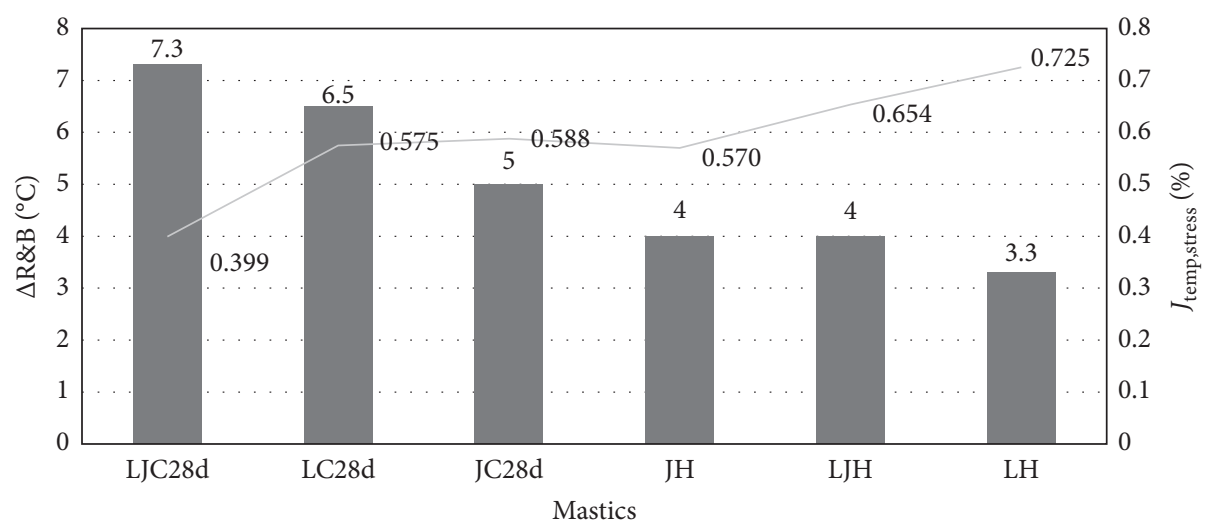

FIGURE 14: Delta ring and ball results compared with $\bar{J}_{\text {temp,stress }}$.

$$
\bar{J}_{\text {temp,stress }}=\frac{1}{n} \sum_{i, j}\left(\frac{\bar{J}_{\mathrm{nrhot} \text { mastici, } j}}{\bar{J}_{\mathrm{nr} B 50 / 70 i, j}}\right) \text {, }
$$

where $\bar{J}_{\text {nr hot mastici, } j}$ refers to $J_{\mathrm{nr}}$ measured for each hot mastic at $i$-th temperature $\left(40^{\circ}\right.$ or $60^{\circ} \mathrm{C}$ ) and $j$-th stress level (see rows 3 to 5 in Table 6$), \bar{J}_{\mathrm{nr} B 50 / 70 i, j}$ refers to $J_{\mathrm{nr}}$ measured for B50/70 at $i$-th temperature $\left(40^{\circ}\right.$ or $\left.60^{\circ} \mathrm{C}\right)$ and $j$-th stress level (see row 1 in Table 6), and $n$ is the number of combined conditions at test temperatures and stress levels equal to 4 in the case study (Table 6):

$$
\bar{J}_{\text {temp,stress }}=\frac{1}{n} \sum_{i, j}\left(\frac{\bar{J}_{\mathrm{nr} \text { cold mastici, } j}}{\bar{J}_{\mathrm{nr} E B 60 / 40 i, j}}\right),
$$

where $\bar{J}_{\text {nr cold mastici, } j}$ refers to $J_{\text {nr }}$ measured for each cold mastic at $i$-th temperature $\left(40^{\circ}\right.$ or $\left.60^{\circ} \mathrm{C}\right)$ and the $j$-th stress level (see rows 6 to 8 in Table 5), $\bar{J}_{\mathrm{nrEB60/40i,j}}$ refers to $J_{\mathrm{nr}}$ measured for EB60/40 at $i$-th temperature $\left(40^{\circ}\right.$ or $\left.60^{\circ} \mathrm{C}\right)$ and the $j$-th stress level (see row 2 in Table 5), and $n$ is the number of combined conditions test temperatures and stress levels equal to 4 in the case study (Table 5).

Firstly, it may be observed that the $\triangle \mathrm{R} \& \mathrm{~B}$ trend is inversely related to $\bar{J}_{\text {temp,stress, }}$ where an increasing $\Delta \mathrm{R} \& \mathrm{~B}$ corresponds to a decreasing $\bar{J}_{\text {temp,stress }}$ : based on the results in Figure 14, the more suitable solution among these mastics (highest $\Delta \mathrm{R} \& \mathrm{~B}$, lowest $\bar{J}_{\text {temp,stress }}$ ) is LJC28d, while the lower performances are found for LH traditional mastics. 


\section{Discussion}

The study described in this paper focuses first of all on the construction of a laboratory mixing protocol for cold bituminous mastics and on the examination of their rheological performance and main differences in terms of shear modulus $G^{*}$ and nonrecoverable creep compliance $J_{\mathrm{nr}}$ when compared to hot mastics. Specifically, the addition of jet grouting waste as a filler for bitumen with and without additional LF led to the best response in cold mastics.

Three filler-to-bitumen ratios (by weight) were investigated, namely, $0.3,0.4$, and 0.5 (Table 3 ); after submitting the cold and hot mastics to centrifuge, no loss of filler was observed for a filler-to-bitumen ratio 0.3 (Table 5). This made it possible to proceed with the analysis by examining the performance of mastics following the ratio mentioned above.

The FS test showed that hot mastics with JW filler (JH and $\mathrm{LJH}$ ) have a higher $G^{*}$ value than traditional LH (Figure 7), with $\delta$ values that do not differ from those obtained from the binder used for the mixing phase, and $G^{*}$ results for all the cold mastics showed that a curing time period of 3 days at $60^{\circ} \mathrm{C}$ in the oven, where $60^{\circ} \mathrm{C}$ is the typical laying temperature for CBM, is not enough to reach a suitable level of mechanical performance in cold mastics (Figure 9). Further curing time at room temperature is needed up to the $28^{\text {th }}$ day to obtain adequate rheological performance; in particular, it was observed how cold mastics with only JW as a filler allow good performance at low temperatures $\left(<30^{\circ} \mathrm{C}\right)$, while JW and limestone fillers should be added to bituminous emulsion at high temperatures (Figure 10).

Since no differences exist between neat bitumen 50/70 and bitumen contained in bituminous emulsion used for mixing cold mastic (with no variations in terms of master curves $G^{*}$ (Figure 8$)$ ), a comparison between the hot and cold mastics was carried out where LJC28d returned greater stiffening behaviour than traditional hot $\mathrm{LH}$ in terms of $G^{*}$.

The deformation recovery capacity of binders and mastics in both hot and cold specimens was assessed using an MSCR test. The nonrecoverable creep compliance $J_{\mathrm{nr}}$ of all mastics was lower than $J_{\mathrm{nr}}$ of bitumen, which indicates the extent of contribution of fillers to increasing the stiffness of the mastics of which they are a component. Specifically, when JW and LF are used as binder fillers for mixing, it was observed that the cold mastics recovered accumulated deformation after the 28th day of curing time at room temperature (LJC28d), showing a $J_{\mathrm{nr}}$ reduction of $74 \%$ at $40^{\circ} \mathrm{C}$ and $52 \%$ at an average temperature of $60^{\circ} \mathrm{C}$ compared to the traditional LH (Table 6). The effect of the stiffness of each mastic produced by adding alternative filler is further confirmed by calculating the following ratio: $J_{\mathrm{nr}}$ mastic with JW filler to $J_{\mathrm{nr}}$ mastic with LF as a filler.

The results showed that the stiffening effect produced by the presence of JW is not stress dependent for either hot and cold mastics but is temperature dependent when moving from $40^{\circ} \mathrm{C}$ to $60^{\circ} \mathrm{C}$ in the case of LJH; LJC28d produced the highest stiffening performance at all test temperatures, and the stress levels allowed a mean reduction of almost $30 \%$ of accumulated deformation compared with traditional $\mathrm{LH}$ (Table 7).

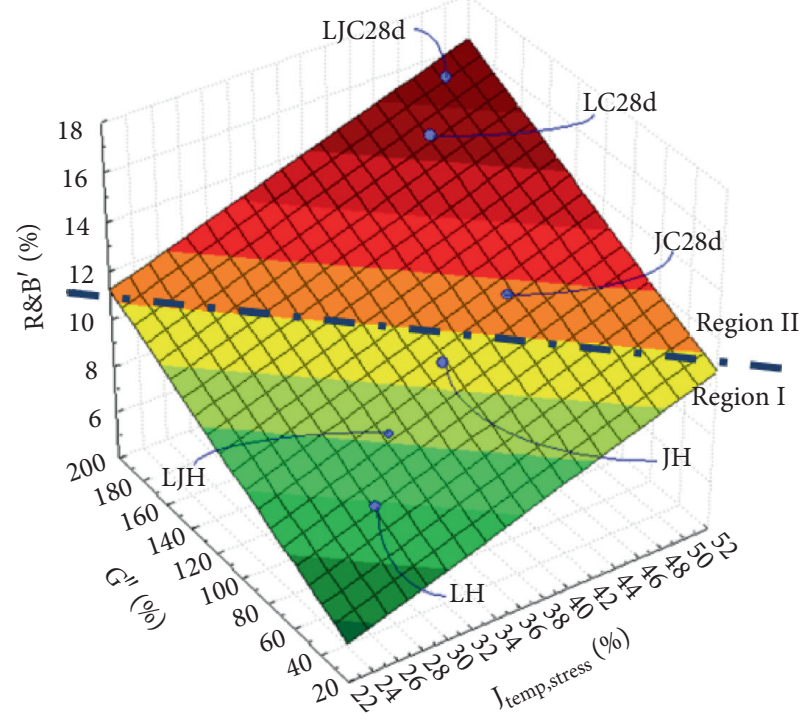

Figure 15: R\&B $B^{\prime}$ against $\bar{J}_{\text {temp,stress }}^{\prime}$ and $G^{* \prime}$.

Based on the observation listed above, the stiffening effect of the fillers in bituminous mastics is summarised in Figure 15; specifically, the stiffening effect was estimated by observing many parameters. Figure 15 shows $R \& B^{\prime}$ vs $\bar{J}_{\text {temp,stress }}^{\prime}$ and $G^{* \prime}$ calculated according to equations (7)-(9), respectively, as follows:

$$
\mathrm{R} \& \mathrm{~B}^{\prime}=\left(\frac{\mathrm{R} \& \mathrm{~B}_{\text {mastic }}}{\mathrm{R} \& \mathrm{~B}_{\text {binder }}}-1\right) \cdot 100,
$$

where $R \& B_{\text {mastic }}$ is the ring and ball value calculated for each mastic (hot and cold) and $R \& B_{\text {binder }}$ is the ring and ball value of each binder (B50/70 for hot mastics and EB60/40 for cold mastics):

$$
J_{\text {temp,stress }}^{\prime}=\left(\bar{J}_{\text {temp,stress }}-1\right) \cdot 100 \text {, }
$$

where $\bar{J}_{\text {temp,stress }}$ is calculated according to equation (5) for hot mastics and equation (6) for cold ones:

$$
G^{* \prime}=\left(\frac{\bar{G}_{\text {mastic }}^{*}}{\bar{G}_{\text {binder }}^{*}}-1\right) \cdot 100,
$$

where $\bar{G}_{\text {mastic }}^{*}$ is the average of the $G^{*}$ values for the test temperatures $40^{\circ}, 50^{\circ}$, and $60^{\circ} \mathrm{C}$ of each mastic (hot and cold) and $\bar{G}_{\text {binder }}^{*}$ is the average of the $G^{*}$ values for the test temperatures $40^{\circ}, 50^{\circ}$, and $60^{\circ} \mathrm{C}$ of each binder (B50/70 for hot mastics and EB60/40 for cold ones).

Figure 15 shows that the stiffening effect of the fillers is different for hot and cold mastics and two different regions of interest emerge. The highest area of region I identified for hot mastics is occupied by JW when it is added to B50/70, while the highest area of region II identified for cold mastics, which is also the peak of the total region, is identified for JW when it is added together with LF into EB. This different filler behaviour for cold and hot mastics may be due to the very high temperature in the hot mastic mixture, which leads to a reduction in the stiffening effect of the fillers within the mastics. 


\section{Conclusions}

On the basis of the results discussed above, the following observations can be made:

(i) Cold mastics mixing jet grouting waste, limestone filler, and bituminous emulsion were made at $60^{\circ} \mathrm{C}$ using a filler-to-bitumen weight ratio of 0.3 ; the separation of bitumen from water into bituminous emulsion took place without the addition of cement as traditionally happens with cold bituminous mixtures; and this is due to the role and contribution of jet grouting waste comprising water, cement, and soil available in site.

(ii) It was observed that cold mastics after 3 days of curing time at $60^{\circ} \mathrm{C}$ return a worse $G^{*}$ performance than neat bitumen 50/70 contained in bituminous emulsion.

(iii) The contribution of the jet grouting waste in terms of $G^{*}$ is higher when it is adopted for hot mastics than cold mastics; the effects of jet grouting waste seriously affects $G^{*}$ when it is added to limestone filler making cold mastics. The last combination allows us to reach a reduction of the phase angle compared to remaining mastics.

(iv) The combination of jet grouting waste and limestone filler in cold mastics increases the stiffness response, returning a higher $G^{*}$ modulus, confirmed also by a reduction of the accumulated deformation obtained from a multistress creep and recovery test.

These conclusions may constitute a starting point for the further study of cold mastics: increasing the filler ratio and changing the type of bituminous emulsion or even adding a rejuvenator; a mastic mixture without using cement could be produced in order to verify the contribution offered by jet grouting waste alone. These will be no more than small-scale analysis results to be transferred full scale in the proportions required to mix cold bituminous mixtures designed without the addition of cement.

\section{Data Availability}

The data used to support the findings of this study are available from the corresponding author upon request.

\section{Disclosure}

The research was carried out within the terms of employment of the authors at Federico II University of Naples.

\section{Conflicts of Interest}

The authors declare that no conflict of interest exists regarding the publication of this paper.

\section{References}

[1] M. Amouzadeh Omrani and A. Modarres, "Stiffness and fatigue behaviour of emulsified cold recycled mixture containing waste powder additives: mechanical and microstructural analysis," Journal of Materials in Civil Engineering, vol. 31, no. 6, Article ID 04019061, 2019.

[2] V. Antunes, A. C. Freire, and J. Neves, "A review on the effect of RAP recycling on bituminous mixtures properties and the viability of multi-recycling," Construction and Building Materials, vol. 211, pp. 453-469, 2019.

[3] S. Du, "Interaction mechanism of cement and asphalt emulsion in asphalt emulsion mixtures," Materials and Structures, vol. 47, no. 7, pp. 1149-1159, 2014.

[4] G. Flores, J. Gallego, L. Miranda, and J. R Marcobal, "Design methodology for in situ cold recycled mixtures with emulsion and 100\% rap," Construction and Building Materials, vol. 216, pp. 496-505, 2019.

[5] S. Du, "Performance characteristic of cold recycled mixture with asphalt emulsion and chemical additives," Advances in Materials Science and Engineering, vol. 2015, Article ID 271596, 2015.

[6] Z. Lyu, A. Shen, X. Qin, X. Yang, and Y. Li, "Grey target optimization and the mechanism of cold recycled asphalt mixture with comprehensive performance," Construction and Building Materials, vol. 198, pp. 269-277, 2019.

[7] K. Kuna and B. Gottumukkala, "Viscoelastic characterization of cold recycled bituminous mixtures," Construction and Building Materials, vol. 199, pp. 298-306, 2019.

[8] C. Godenzoni, M. Bocci, and A. Graziani, "Rheological characterization of cold bituminous mastics produced with different mineral additions," Transport Infrastructure and Systems: Proceedings of the AIIT International Congress on Transport Infrastructure and Systems, p. 185, Rome, Italy, 2017.

[9] V. Vignali, F. Mazzotta, C. Sangiorgi, A. Simone, C. Lantieri, and G. Dondi, "Rheological and 3D DEM characterization of potential rutting of cold bituminous mastics," Construction and Building Materials, vol. 73, pp. 339-349, 2014.

[10] E. Garilli, F. Autelitano, and F. Giuliani, "Use of bending beam rheometer test for rheological analysis of asphalt emulsioncement mastics in cold in-place recycling," Construction and Building Materials, vol. 222, pp. 484-492, 2019.

[11] M. Elnasri, G. Airey, and N. Thom, "Experimental investigation of bitumen and mastics under shear creep and creeprecovery testing," in Airfield and Highway Pavement 2013: Sustainable and Efficient Pavements, pp. 921-932, American Society of Civil Engineers, Reston, VA, USA, 2013.

[12] G. Dondi, F. Mazzotta, C. Sangiorgi et al., "Influence of cement and limestone filler on the rheological properties of mastic in cold bituminous recycled mixtures," Sustainability, Eco-Efficiency, and Conservation in Transportation Infrastructure Asset Management, vol. 61, 2014.

[13] H. Soenen, T. Blomberg, T. Pellinen, and O.-V. Laukkanen, "The multiple stress creep-recovery test: a detailed analysis of repeatability and reproducibility," Road Materials and Pavement Design, vol. 14, no. sup1, pp. 2-11, 2013.

[14] F. Cardone, F. Frigio, G. Ferrotti, and F. Canestrari, "Influence of mineral fillers on the rheological response of polymermodified bitumens and mastics," Journal of Traffic and Transportation Engineering (English Edition), vol. 2, no. 6, pp. 373-381, 2015.

[15] A. Foroutan Mirhosseini, A. Kavussi, M. H. Jalal Kamali, M. M. Khabiri, and A. Hassani, "Evaluating fatigue behavior 
of asphalt binders and mixes containing date seed ash," Journal of Civil Engineering and Management, vol. 23, no. 8, pp. 1164-1175, 2017.

[16] C. Hintz and H. Bahia, "Simplification of linear amplitude sweep test and specification parameter," Transportation Research Record: Journal of the Transportation Research Board, vol. 2370, no. 1, pp. 10-16, 2013.

[17] A. Foroutan Mirhosseini, A. Kavussi, S. A. Tahami, and S. Dessouky, "Characterizing temperature performance of bio-modified binders containing RAP binder," Journal of Materials in Civil Engineering, vol. 30, no. 8, 2018.

[18] A. Graziani, C. Godenzoni, F. Cardone, and M. Bocci, "Effect of curing on the physical and mechanical properties of coldrecycled bituminous mixtures," Materials \& Design, vol. 95, pp. 358-369, 2016.

[19] S. Ullah and B. F. Tanyu, "Methodology to develop design guidelines to construct unbound base course with reclaimed asphalt pavement (RAP)," Construction and Building Materials, vol. 223, pp. 463-476, 2019. 